\title{
Oesophageal high-resolution manometry: moving from research into clinical practice
}

\author{
M R Fox, ${ }^{1,2}$ A J Bredenoord ${ }^{3}$
}

${ }^{1}$ Clinic for Gastroenterology and Hepatology, University Hospital Zürich, Zürich, Switzerland;

${ }^{2}$ Oesophageal Laboratory \& Department of Gastroenterology, St. Thomas' Hospital, London, UK; ${ }^{3}$ Department of Gastroenterology, Sint Antonius Hospital, Nieuwegein, The Netherlands

Correspondence to: Dr Mark R. Fox, Clinic for Gastroenterology and Hepatology, University Hospital Zürich, CH-4103 Zürich, Switzerland; dr.mark.fox@ gmail.com

Revised 17 August 2007 Accepted 23 August 2007 Published Online First 25 September 2007

\section{Summary: High-resolution manometry}

- High-resolution manometry (HRM) is a recent development made possible by catheters with closely spaced $(<2 \mathrm{~cm})$ pressure sensors

- HRM reveals the complex functional anatomy of oesophageal peristalsis and the oesophagogastric junction

- "Spatiotemporal plots" derived from HRM data provide objective measurements of the forces that drive food and fluid from the pharynx to the stomach

- HRM improves the ability to predict the success or failure of bolus movement through the oesophagus compared to conventional manometry (and the occurrence of reflux events)

- The components of the anti-reflux barrier (lower oesophageal sphincter and crural diaphragm) can be distinguished and their dynamic interaction can be studied

- Overall diagnostic agreement between HRM and conventional manometry is high; however, HRM increases diagnostic yield especially in cases of functional dysphagia

- Measurement of the oesophago-gastric pressure gradient increases diagnostic accuracy for achalasia and differentiates oesophageal spasm from rapid elevation of the intra-bolus pressure due to focal dysmotility or impaired LOS function

\section{ABSTRACT}

Manometry measures pressure within the oesophageal lumen and sphincters, and provides an assessment of the neuromuscular activity that dictates function in health and disease. It is performed to investigate the cause of functional dysphagia, unexplained "non-cardiac" chest pain, and in the pre-operative work-up of patients referred for anti-reflux surgery. Manometric techniques have improved in a step-wise fashion from a single pressure channel to the development of high-resolution manometry (HRM) with up to 36 pressure sensors. At the same time, advances in computer processing allow pressure data to be presented in real time as a compact, visually intuitive "spatiotemporal plot" of oesophageal pressure activity. HRM recordings reveal the complex functional anatomy of the oesophagus and its sphincters. Spatiotemporal plots provide objective measurements of the forces that move food and fluid from the pharynx to the stomach and determine the risk of reflux events. The introduction of

\footnotetext{
determine the risk of reflux events. The introduction of
}

commercially available HRM has been followed by rapid uptake of the technique. This review examines the current evidence that supports the move of HRM from the research setting into clinical practice. It is assessed whether a detailed description of pressure activity identifies clinically relevant oesophageal dysfunction that is missed by conventional investigation, increasing diagnostic yield and accuracy. The need for a new classification system for oesophageal motor activity based on HRM recordings is discussed. Looking ahead the potential of this technology to guide more effective medical and surgical treatment of oesophageal disease is considered because, ultimately, it is this that will define the success of HRM in clinical practice.

\section{DEVELOPMENT OF MANOMETRY TECHNOLOGY}

The ideal manometric system would acquire continuous, high-fidelity pressure data from the pharynx to the stomach with circumferential sensitivity. The equipment should be cheap. The procedure should be quick and easy to perform and analyse. Presentation of pressure data should display not only oesophageal contractility but provide an accurate assessment of the forces that drive bolus movement, ${ }^{12}$ and identify (or exclude) abnormal oesophageal function as the cause of a patient's symptoms.

Technological advances in manometry and image processing have moved towards this "ideal" since the first description of intra-oesophageal pressure measurement in the late 19th century. Each advance has brought new insights. Balloontipped catheters provided the first, rudimentary, measurements of oesophageal function in animals and humans. In the first half of the 20th century bundles of non-perfused, open-tipped catheters were used to observe propulsive, peristaltic contractions. The introduction of low-compliance, pneumo-hydraulic perfusion systems and side-hole catheters increased measurement accuracy. Convenient, solid-state catheters with intraluminal transducers were also introduced. These developments led to the adoption of manometry in clinical practice; however, stable measurements of the pharyngo-oesophageal segment and lower oesophageal sphincter (LOS), especially during swallowing and LOS relaxation, remained difficult due to movement of the sphincter relative to point pressure sensors. In 1956, Fyke and colleagues introduced the station pull-through technique to
This paper is freely avalab online under the BMJ Journals unlocked scheme, see http:// gut.bmj.com/info/unlocked.dtl 
ensure that LOS pressure was sampled reliably as the sensor passed through the high-pressure zone. ${ }^{3}$ This method is still in wide use; however, the pullthrough is time-consuming, not well tolerated, has effects on LOS pressure, and cannot be used to assess LOS movement or relaxation. ${ }^{4}$ This problem was solved first in 1976 by Dent with the introduction of a perfused sleeve sensor that signals the greatest pressure along its length, so that maximum LOS pressure is measured continuously. ${ }^{5}$ Extensive literature supports this method for monitoring of LOS pressure and recognition of spontaneous, transient LOS relaxations (TLOSRs) as the most common mechanism of gastrooesophageal reflux. ${ }^{67}$

For adult humans, a $6 \mathrm{~cm}$ sleeve is usually adequate, though oesophageal shortening during spasm and reflux events occasionally causes excursion of the LOS which exceeds the length of the sleeve. ${ }^{89}$ Current guidelines recommend pressure monitoring with four to eight sensors including a sleeve sensor as the current "gold standard" for oesophageal studies (defined as "conventional manometry" in this review). ${ }^{10}{ }^{11}$ Nevertheless, due to the inconvenience of water-perfused techniques, many clinical motility laboratories continue to use solid state catheters with widely spaced "point" pressure sensors that fail to compensate for sphincter movement and do not provide reliable measurements of swallow or spontaneous LOS relaxations. ${ }^{4}$

\section{“CONVENTIONAL MANOMETRY"}

Despite the technical advances described above, "conventional manometry" is not the ideal investigation of oesophageal function (table 1). Moreover, considerable time and expertise are required to obtain a technically adequate and maximally informative study of oesophageal function by these techniques.

At present, abnormal motor activity is defined in terms of a few basic patterns seen in oesophageal manometry: incomplete sphincter relaxation, oesophageal spasm, hypertensive contractions, and loss of tone and motility. ${ }^{12}{ }^{13}$ This classification is simple; however, even for experienced physiologists in specialist centres, inter-observer agreement

Table 1 Comparison of manometric methods

\begin{tabular}{|c|c|c|c|}
\hline & $\begin{array}{l}\text { Conventional } \\
\text { pull-through } \\
\text { manometry }\end{array}$ & $\begin{array}{l}\text { Conventional } \\
\text { sleeve } \\
\text { manometry }\end{array}$ & $\begin{array}{l}\text { High-resolution } \\
\text { manometry }\end{array}$ \\
\hline Cost & Inexpensive & Inexpensive & Expensive \\
\hline Execution & $\begin{array}{l}\text { Relatively } \\
\text { elaborate } \\
\text { and time } \\
\text { consuming }\end{array}$ & $\begin{array}{l}\text { Relatively } \\
\text { elaborate } \\
\text { and time } \\
\text { consuming }\end{array}$ & $\begin{array}{l}\text { Relatively } \\
\text { simple and } \\
\text { fast }\end{array}$ \\
\hline Interpretation & $\begin{array}{l}\text { Requires } \\
\text { experience }\end{array}$ & $\begin{array}{l}\text { Requires } \\
\text { experience }\end{array}$ & Relatively easy \\
\hline $\begin{array}{l}\text { Measuring LOS } \\
\text { function and } \\
\text { relaxation }\end{array}$ & Limited & Yes & Yes \\
\hline $\begin{array}{l}\text { Measuring UOS } \\
\text { function and } \\
\text { relaxation }\end{array}$ & No & Limited & Yes \\
\hline
\end{tabular}

in the interpretation of manometric measurements is poor. ${ }^{14}$ Only achalasia and severe diffuse oesophageal spasm are specific disorders with manometric abnormalities that are absent in healthy subjects. Other oesophageal motility disorders are poorly defined, often include "abnormalities" that can be found in symptom-free individuals as well, ${ }^{15}{ }^{16}$ and are inconsistent over time. ${ }^{17}$ Moreover, the association between conventional manometric findings, symptom severity and course of disease is poor. ${ }^{18-20}$ Thus the clinical significance of oesophageal dysmotility is often uncertain and many diagnoses based on conventional manometry are subjective, based as much on the clinical presentation as the objective pressure recordings.

\section{HIGH-RESOLUTION MANOMETRY}

The foundations of HRM were laid in the early 1990s by Clouse and Staiano. In a series of studies pressure activity was assessed for several swallows at closely spaced positions through the oesophagus. Time, catheter position and average pressure were then reconstructed into pseudo-3D "topographic plots" that demonstrated the functional anatomy of the oesophagus (fig 1). ${ }^{21-23}$ Similar studies examined the gastro-oesophageal junction. ${ }^{24}$ However, in common with all pull-through techniques, only a snap-shot view of oesophageal

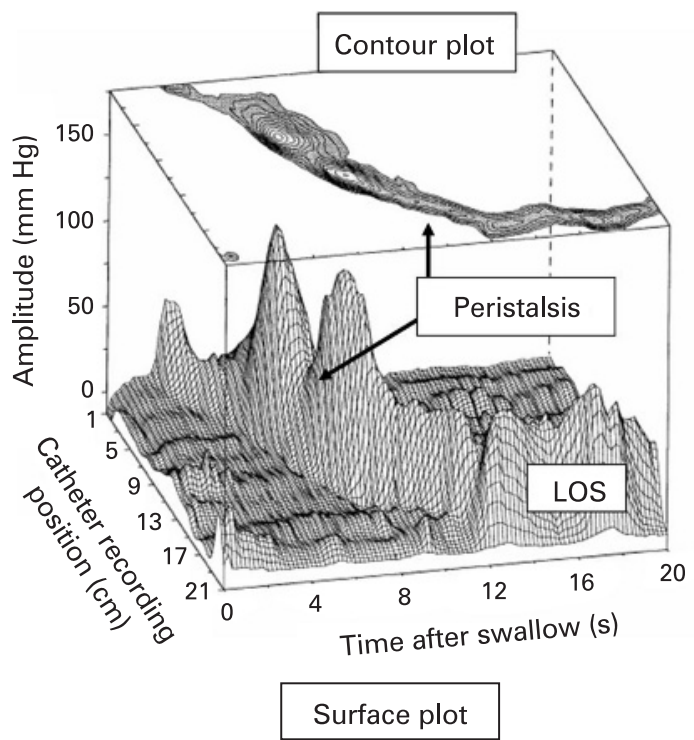

Figure 1 Example of topographic display of normal oesophageal pressure data reconstructed from separate measurements at multiple levels during a station pullthrough. The pseudo-3D surface plot displays the characteristic peaks and troughs of the peristaltic pressure wave proceeding from the proximal oesophagus (background), until it merges with the LES aftercontraction (foreground). The contour plot of the same swallow superimposed at the top of the figure demonstrates how 3D data are represented using concentric rings at $10 \mathrm{~mm} \mathrm{Hg}$ intervals to indicate increasing amplitudes. (Reproduced from Clouse and Staiano, ${ }^{22}$ with permission.) 
motility was provided and intermittent events could not be studied.

An adequate description of oesophageal and LOS pressure activity requires continuous recordings from a large number of closely spaced pressure sensors. The advent of "true" high-resolution manometry came with the development of micro-manometric water-perfused assemblies with 21-32 channels and, ${ }^{25}{ }^{26}$ more recently, novel solidstate technology that allowed construction of catheters with up to 36 pressure sensors. ${ }^{27-29}$ At the same time, advances in computer technology allowed the large volume of data acquired by HRM to be presented in real time not only as conventional "line plots", but also as "spatiotemporal plots" (sometimes referred to as a "contour" or "topographic" plots) that display the direction and force of oesophageal pressure activity (fig 2). An electronic "e-sleeve" can be applied during data analysis to provide stable measurements of LOS function similar to that acquired by a conventional sleeve sensor. ${ }^{87}$

On a theoretical level, HRM provides advantages over conventional techniques for the assessment of oesophageal function (box 1). Firstly, HRM reveals the dynamic action of the upper oesophageal sphincter, the segmental character of oesophageal peristalsis and the functional anatomy of the oesophago-gastric junction. Secondly, spatiotemporal plots constructed from data acquired by closely spaced pressure sensors $(\leqslant 2 \mathrm{~cm})$ provide an accurate representation of the relationship between closure force (contractile pressure), clearance force (intra-bolus pressure) and outflow resistance (nadir pressure and pressure gradient across the oesophago-gastric junction). ${ }^{28} 29$ All these factors are required to fully appreciate the biomechanics of bolus transport. The pattern of oesophageal peristalsis and sphincter activity defines whether oesophageal motor activity is normal or abnormal. The intra-bolus pressure and oesophago-gastric pressure gradient define whether or not this activity is consistent with effective function.

On a practical level, HRM makes it easy to acquire good quality pressure measurements from the oesophagus, facilitates positioning of the catheter and removes the need for a pull-through procedure (box 2). Moreover spatiotemporal plots of pressure information make it easy to identify normal and abnormal patterns of oesophageal motility (fig 3).

\section{HIGH-RESOLUTION MANOMETRY IN PHYSIOLOGICAL STUDIES}

High-resolution pressure measurement is a useful research tool for mechanistic studies of oesophageal function (box 1). The contribution of HRM to physiological and medical research is considered separately, although this is an artificial distinction because clinical pathology often provides a model for hypothesis-driven investigations.

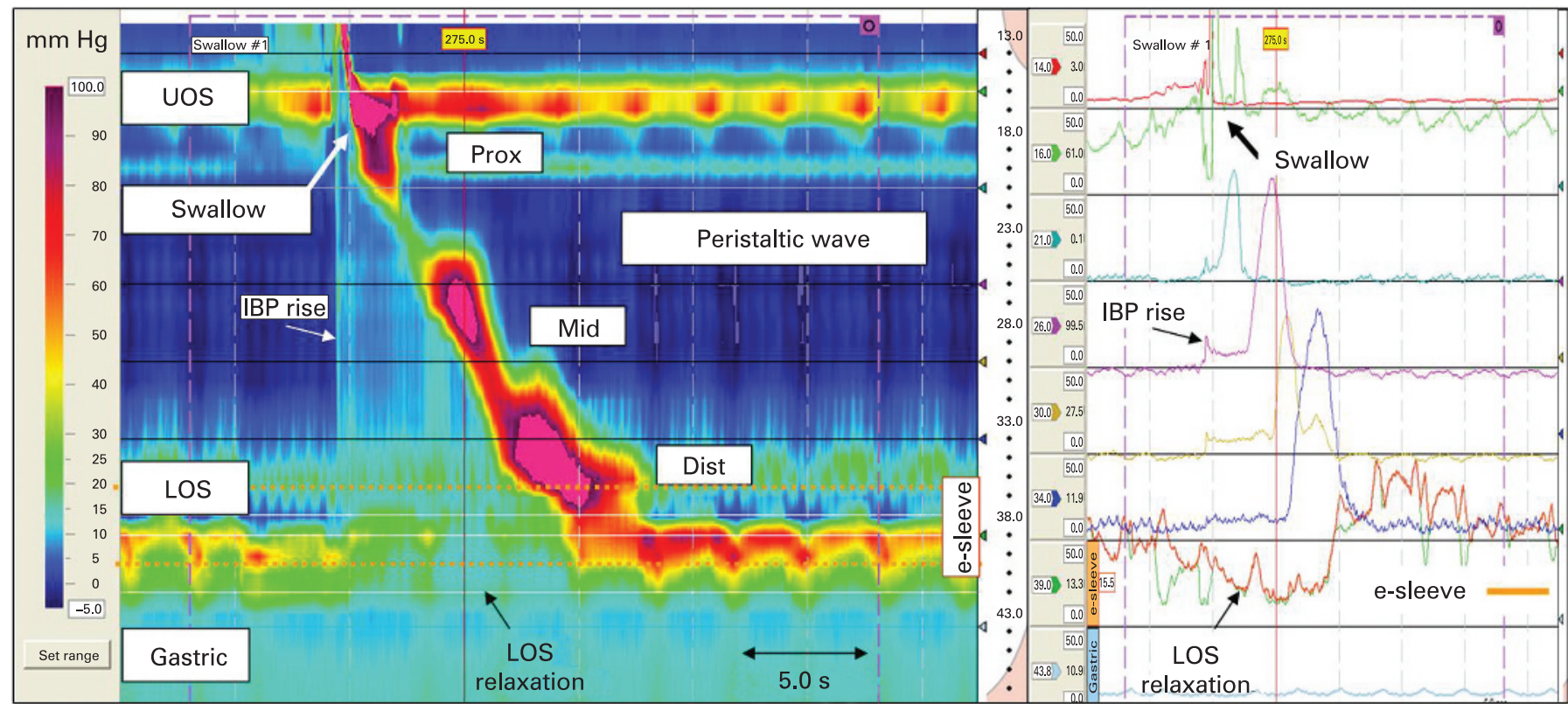

Figure 2 High-resolution manometry depicts oesophageal pressure activity from the pharynx to the stomach. The spatiotemporal plot presents the same information as presented in the line plots. Time is on the $\mathrm{x}$-axis and distance from the nares is on the $y$-axis. Each pressure is assigned a colour (legend left). The segmental functional anatomy of oesophagus is seen. The synchronous relaxation of the upper oesophageal sphincter (UOS) and lower oesophageal sphincter (LOS) is obvious, as is the increasing pressure and duration of the peristaltic wave as it passes distally. The intra-bolus pressure (IBP) compartmentalised between the peristaltic wave and oesophago-gastric junction and pressure gradient across the gastro-oesophageal junction are visualised. The virtual "e-sleeve" application provides a summary measurement of LOS pressure and relaxation (bold brown line plot). Similar to a conventional sleeve sensor, the maximum pressure over a $6 \mathrm{~cm}$ distance is displayed. (Images acquired by 36 -channel SSI Manoscan 360 .) 


\section{Box 1 HRM: advances in the research setting}

Follows the dynamic movement and function of the pharyngeal swallow

Reveals the segmental functional anatomy of the oesophagus

Provides objective measurements of the forces affecting bolus transport

- Distinguishes the LOS and diaphragmatic components of the anti-reflux barrier and follows their movement and interaction over time

- Facilitates measurements of gastric, pyloric and small bowel contractility

\section{Box 2 HRM: practical advantages and disadvantages}

\section{Advantages}

- Quick and easy positioning of catheter, pull-through not required

- Movement of the catheter relative to the LOS does not impair data quality

- Facilitates positioning of the $\mathrm{pH}$ probe for reflux studies

- Decreases time required for study procedure

- Normal and abnormal function easy to recognise on spatiotemporal plot

Disadvantages

- Expensive equipment

- Lack of experience with spatiotemporal plots brings risk of over-diagnosis of functionally insignificant oesophageal dysmotility

\section{Pharyngeal swallow}

Characteristics of the pharyngeal swallow are hard to study using conventional manometry. Elevation of the pharynx during swallowing makes manometry of the upper oesophageal sphincter (UOS) subject to movement artifacts, rendering measurements with a single point pressure sensor useless in the region. Since the pharynx and UOS consist of striated muscle, measurement equipment must have a very rapid response time, which is not the case for sleeve sensor manometry. HRM meets both requirements. Studies using simultaneous HRM and video-fluoroscopy have provided detailed information on the biomechanics of the pharyngeal swallow and clarify the interaction between these properties and bolus volume and consistency. ${ }^{30}{ }^{31}$ These described in unprecedented detail how the UOS accommodates large-volume swallows by opening wider and for longer to maintain intra-bolus pressure within a narrow physiological range, ${ }^{30}$ and how abnormal structure or function in this region increase resistance to flow and markedly raise the forces required to drive bolus passage..$^{31}$ Moreover, the position of the maximum intra-bolus pressure gradient co-locates precisely with obstructive pathology (fig 4). ${ }^{31}$ Thus HRM measurements confirm the location and functional significance of pathology within the pharyngooesophageal segment seen on video-fluoroscopy.

\section{Oesophageal peristalsis}

The pharyngeal swallow is accompanied by reflex oesophageal and LOS relaxation, "deglutative inhibition", which allows the bolus to pass through the oesophagus with minimal resistance..$^{32-34}$ This is followed by a wave of "excitation" and peristaltic contraction that clears the bolus from the lumen Previously, it was assumed that clearance is completed by a single continuous contraction; however, in the 1980s it was shown that chronic bolus retention at the level of the aortic arch was accompanied by weak contraction in the midoesophagus. ${ }^{356}$ Mathematical models based on this data suggested the presence of distinct proximal and distal contraction waves. ${ }^{37}$ Recently, detailed spacetime analysis of concurrent HRM and fluoroscopic images confirmed that the pressure trough at the level of the aortic arch represents a "transition zone" in which the proximal contraction wave originating in the striated oesophagus terminates, and below which a distal contraction wave simultaneously forms and propagates into the smooth-muscle oesophagus..$^{38}$ Follow-up studies in patients with impaired oesophageal clearance (reflux oesophagitis) showed that chronic bolus escape at this level is associated with wide separation of the proximal and distal contraction waves and reduced contractile force within the transition zone. ${ }^{39}$ Weak midoesophageal contraction (proximal smooth-muscle segment) appears to be the cause of impaired clearance function in these patients, ${ }^{39}$ and this is supported by the finding that the 5-HT4 agonist tegaserod improved bolus transport by enhancing contractility at this level. ${ }^{40}$ Thus HRM has confirmed that bolus clearance is achieved by coordinated contractions in functionally distinct oesophageal segments and that abnormal motility can be restricted to specific segments. For example, whereas hypotensive motility in the mid-oesophagus is a cause of bolus escape at the level of the aortic arch, hypertensive ("nutcracker") and repetitive spastic contractions are often restricted to the distal oesophagus..$^{41}$ Furthermore, HRM studies in humans have reproduced and clarified the findings of classic animal experiments, ${ }^{43}{ }^{44}$ that pharmacological agents have differential effects along the length of the oesophagus. The mid-oesophagus is responsive to pro-cholinergic agents like cisapride and tegaserod, ${ }^{23}{ }^{40}$ whereas the distal oesophagus is more sensitive to non-adrenergic, non-cholinergic effects (e.g. nitrinergic) ${ }^{45}$

\section{Oesophago-gastric junction}

HRM facilitates the investigation of the oesophago-gastric junction because a pull-through is not required and the borders of the oesophagogastric junction are easily recognised (even when unstable). With intraluminal pressure measured by closely spaced sensors $(\leqslant 1 \mathrm{~cm})$, two separate highpressure zones at the oesophago-gastric junction can be visualised in patients with a hiatal hernia, ${ }^{46-48}$ and the dynamic interaction of the intrinsic (LOS) and extrinsic sphincter (crural diaphragm), can be followed (fig 5).

Prolonged monitoring of LOS pressure with a sleeve sensor identified TLOSRs as the most important mechanism by which reflux occurs in healthy subjects and in patients with mild to moderate gastro-oesophageal reflux disease (GORD). ${ }^{679} \mathrm{HRM}$ is at least as accurate as sleeve 

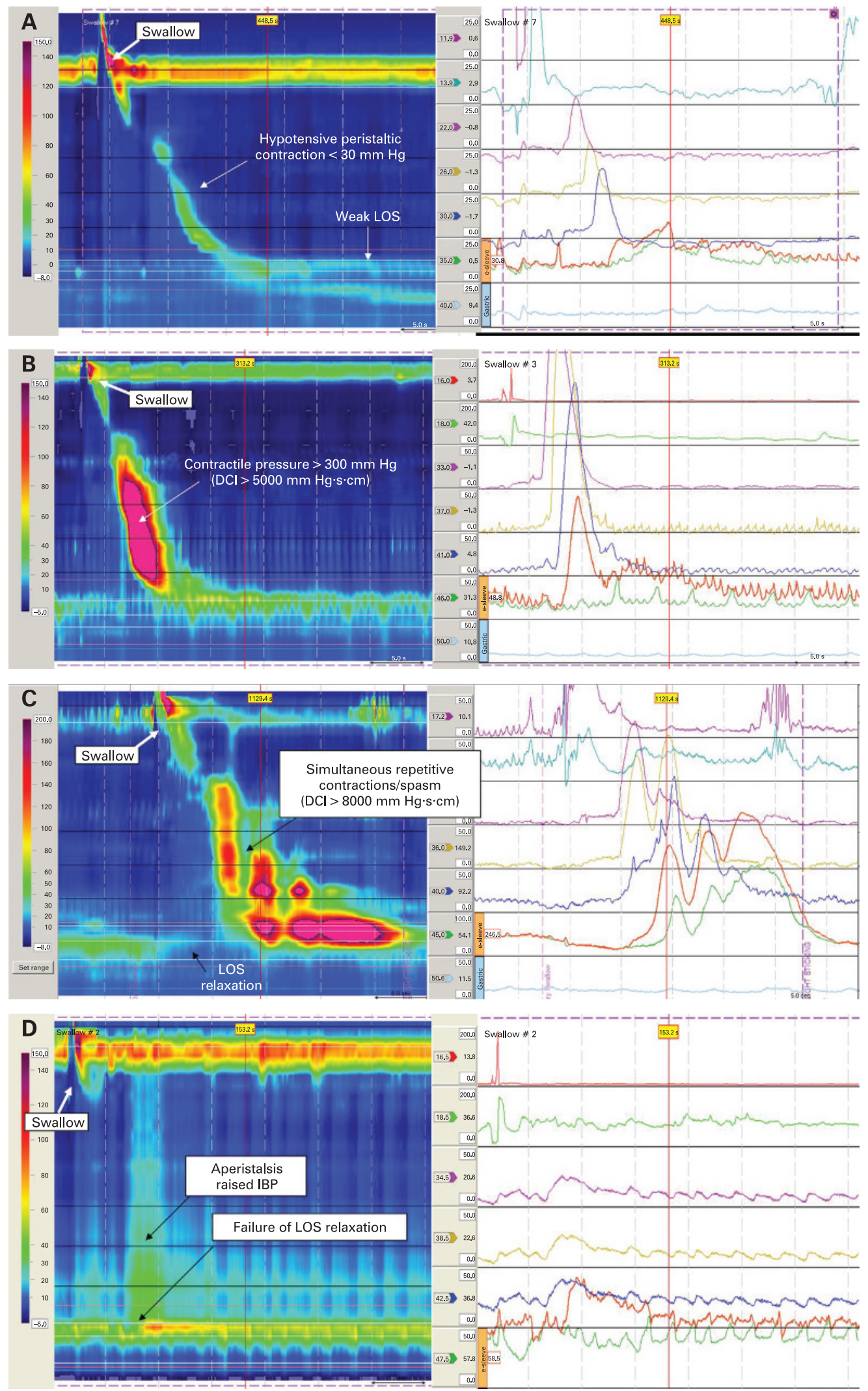

Figure 3 Spatiotemporal plots and conventional line plots with e-sleeve (bold brown line plot) derived from the same swallows in patients with well-defined oesophageal dysmotility are presented. (Images acquired by 36-channel SSI Manoscan 360.) (A) Hypotensive lower oesophageal sphincter and peristaltic contraction ( $<30 \mathrm{~mm} \mathrm{Hg}$ ) in a patient with intermittent sensation of dysphagia, retrosternal bolus escape and mild-moderate reflux symptoms. (B) Hypertensive contraction ("nutcracker oesophagus") in a patient with intermittent non-cardiac chest pain and normal oesophageal acid exposure. Propulsive peristalsis and OGJ relaxation are preserved; however, contractile pressure is greatly elevated with peak pressure $>260 \mathrm{~mm} \mathrm{Hg}$ and distal contractile integral (DCl) $>5000 \mathrm{~mm}$ $\mathrm{Hg} \cdot \mathrm{s} \cdot \mathrm{cm}$ (see table 2). (C) Diffuse oesophageal spasm in a patient with dysphagia and chest pain, especially with solid foods. High-pressure, simultaneous and repetitive contractions (pressure $>300 \mathrm{~mm} \mathrm{Hg}, \mathrm{DCl}>8000 \mathrm{~mm} \mathrm{Hg} \cdot \mathrm{s} \cdot \mathrm{cm}$ ) are present; LOS relaxation is preserved. (D) Classic achalasia in a patient with progressive dysphagia to solids and liquids. There is raised baseline LOS pressure ( $50 \mathrm{~mm} \mathrm{Hg})$ with aperistalsis and failed LOS relaxation on swallowing. 

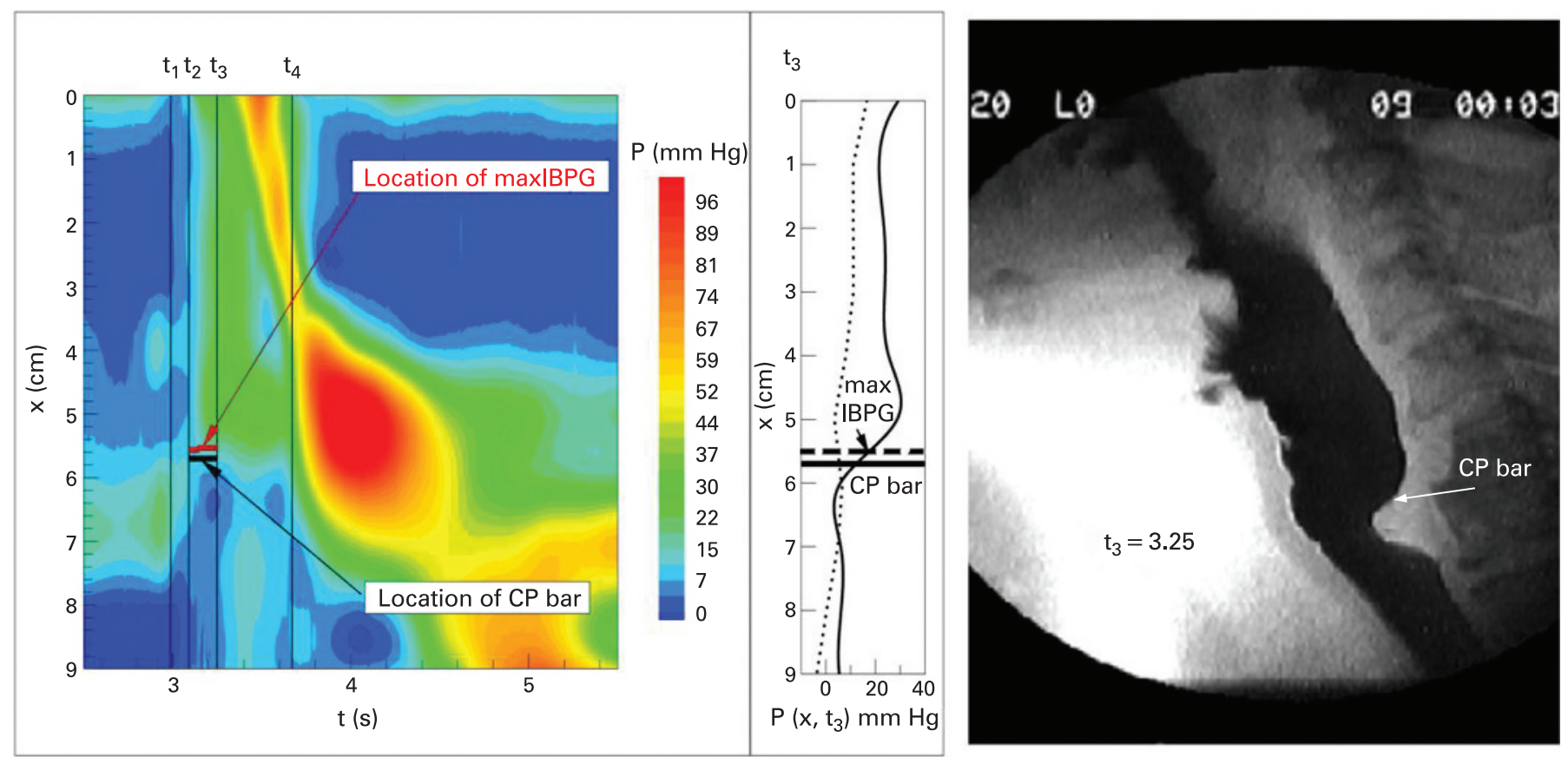

Figure 4 Concurrent radiograph and HRM in a patient with pharyngeal dysphagia. A cricopharyngeal (CP) bar is seen on the radiograph taken at $\mathrm{t} 3$, at the same position as the maximum intra-bolus pressure gradient (IBPG; indicated on axial pressure plot (centre)). This co-location confirms that the CP bar represents a significant functional obstruction to flow through the pharyngo-oesophageal segment. (Reproduced from Pal et al, ${ }^{31}$ with permission.)

sensor manometry for the detection of TLOSRs (fig 6) and other events that compromise the reflux barrier, ${ }^{50}$ and has shed new light on GORD pathophysiology. Mechanistic studies using concurrent HRM and radiography in which the squamo-columnar junction was marked with metal clips, documented that the key events leading to opening of the reflux barrier during TLOSRs were, in addition to LOS relaxation, crural diaphragm inhibition, oesophageal shortening, and a positive pressure gradient between the stomach and the oesophagus lumen. ${ }^{48}$ Initial studies suggested that the trans-sphincteric pressure gradient was larger during TLOSRs accompanied by gastrooesophageal reflux compared to those without evidence of reflux; ${ }^{51}$ however, this has not been confirmed $^{52}$ and preliminary evidence suggests that other factors, including "structural" changes at the gastric cardia, may determine the risk of reflux during these events. ${ }^{53}$

Concurrent HRM and radiography in patients with GORD have shown also that the distance between LOS and diaphragm is unstable over time. $^{47}$ The integrity of the oesophago-gastric junction is compromised by spatial separation between these components of the reflux barrier, and the occurrence of reflux events is doubled during these periods by mechanisms other than TLOSRs (fig 7). ${ }^{47}$ Clinical studies confirm that progressive separation between the LOS and diaphragm (irrespective of the presence or absence of an obvious hiatus hernia on endoscopy) is associated with increasing oesophageal acid exposure,$^{54}$ especially in obese patients in whom the effect is exacerbated by increased gastric pressure, ${ }^{55}$ and frequency of TLOSRs. ${ }^{56}$
In addition to the assessment of reflux disease, measurement of the pressure gradient across the oesophago-gastric junction is an accurate method for detecting impaired sphincter function, which is unaffected by sphincter asymmetry and axial movement during oesophageal shortening and spasm. ${ }^{57}$ During normal bolus transport the pressure difference between the oesophagus and stomach is small; however, the presence of an elevated oesophago-gastric pressure gradient can identify and quantify the resistance to flow across the LOS due to impaired relaxation (i.e. achalasia) or restricted opening (e.g. stricture, post-fundoplication). ${ }^{57} 58$

\section{FROM PRESSURE MEASUREMENTS TO OESOPHAGEAL FUNCTION}

The ability of HRM to establish an objective link between pressure measurements and bolus movement (or reflux events) represents a paradigm shift in the approach to and interpretation of manometric data. This is important because failed bolus transport and poor reflux clearance are more closely related to oesophageal symptoms and mucosal damage than abnormal motor function per se..$^{50}$ A head-to-head comparison between conventional and high-resolution manometry found that the latter was more accurate at predicting the presence of disturbed bolus transport on video-fluoroscopy, especially at mild-tomoderate levels of oesophageal dysfunction (both techniques identified normal swallows and gross dysfunction). ${ }^{8}$ In this study the advantage of HRM was explained by improved detection of focal dysmotility, confirming that functionally important motor abnormalities can be limited to a short 
Figure 5 Spatiotemporal plot from a patient with a hiatus hernia and reflux symptoms. The oesophago-gastric junction is divided into the proximal intrinsic LOS (iLOS) and distal crural LOS (cLOS) The "double pressure bump", as seen on a "pullthrough", is seen in the axial pressure plot (right panel). Pressure along the $\mathrm{x}$-axis placed at the level of the iLOS and cLOS are displayed (lower panel); the synergistic changes in pressure during respiration are demonstrated. (Images acquired by 32-channel AMS/Dentsleeve equipment.)

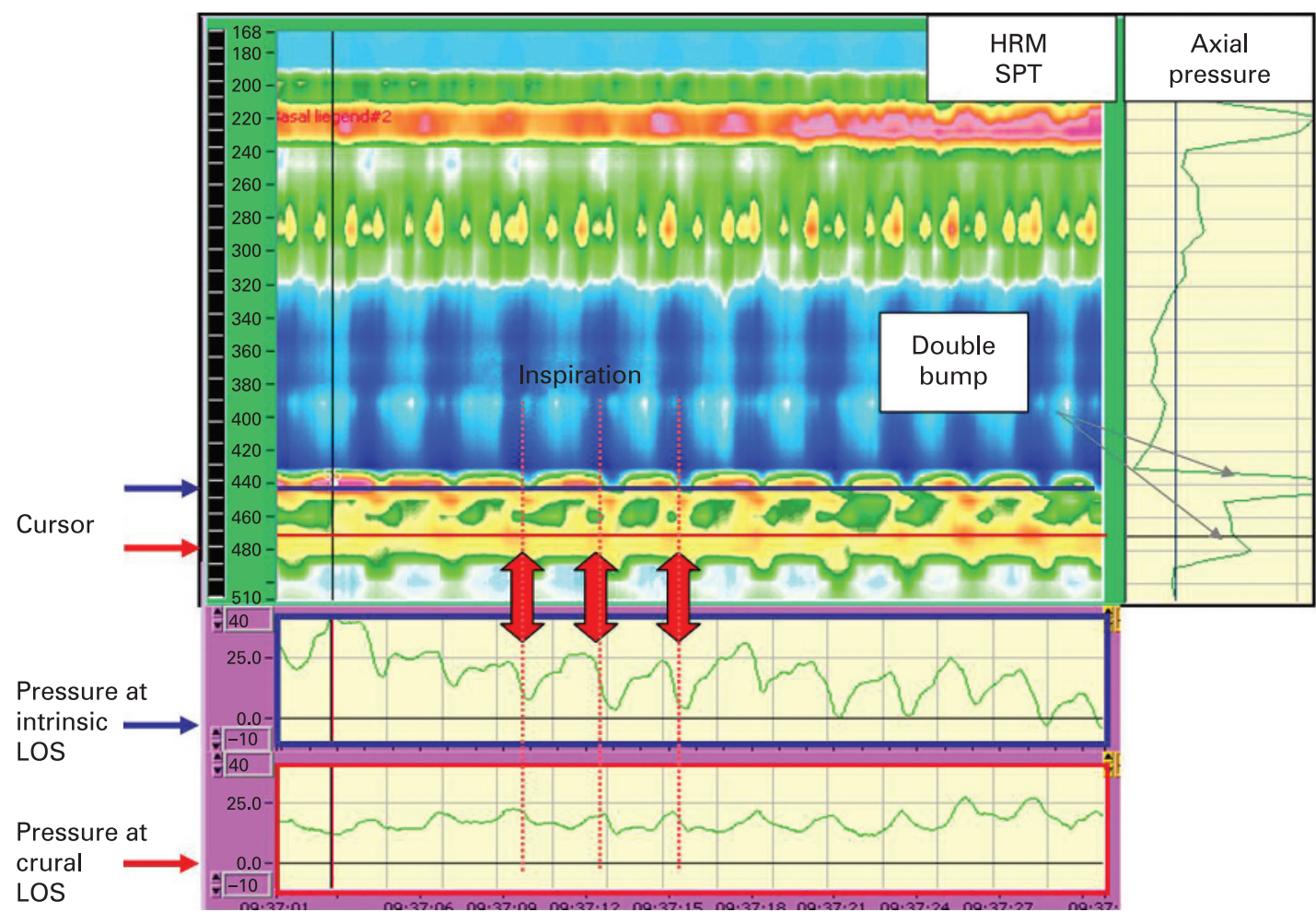

segment of the oesophagus and will be missed by pressure sensors placed too far apart. ${ }^{6162}$ This conventional analysis focuses on peristaltic and LOS contractile pressure; however, the advantages of HRM may be even more apparent if a fluid mechanical perspective on oesophageal function is applied. ${ }^{2}$ Mathematical algorithms have been developed that describe HRM measurements in terms of functionally relevant attributes of pressure activity. ${ }^{63}$ For example, the integrated relaxation resistance (IRR) expresses the period of time during LOS relaxation that the oesophago- gastric pressure gradient is positive and consistent with propulsive flow (fig 8). ${ }^{64}$ This is a complex parameter, and a simple measurement such as LOS nadir pressure may well be adequate in routine studies; however, preliminary results suggest that the IRR improves the ability to identify and categorise patients with functional dysphagia. ${ }^{6566}$

\section{HIGH-RESOLUTION MANOMETRY IN CLINICAL PRACTICE}

Oesophageal manometry is used to investigate oesophageal symptoms after mechanical obstruc-

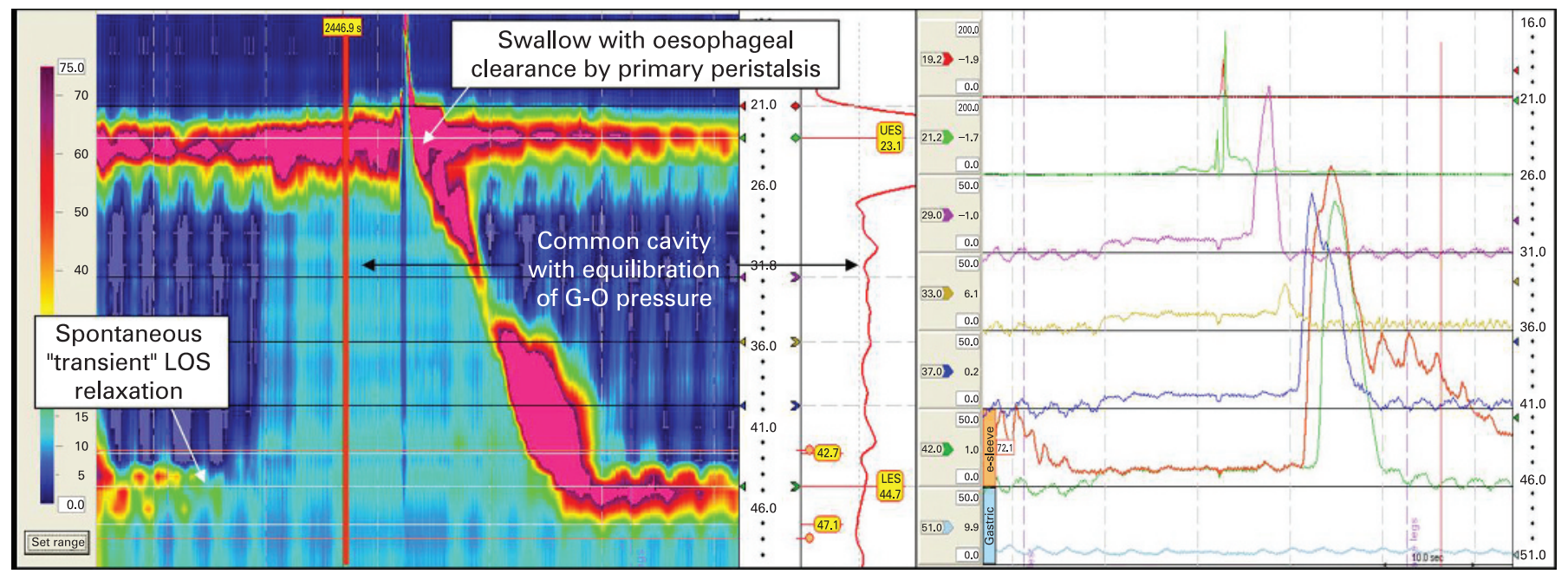

Figure 6 HRM spatiotemporal plot demonstrates spontaneous, transient LOS relaxation followed shortly afterwards by a common cavity indicating reflux. Equilibration of gastro-oesophageal pressure is obvious on the axial pressure plot at the position of the red cursor on the spatiotemporal plot (centre). These events are also observed on conventional sleeve manometry (right). The event is terminated and oesophagus cleared by primary peristalsis with intra-oesophageal pressure returning to baseline levels. (Images acquired by 36-channel SSI Manoscan 360.) 
A

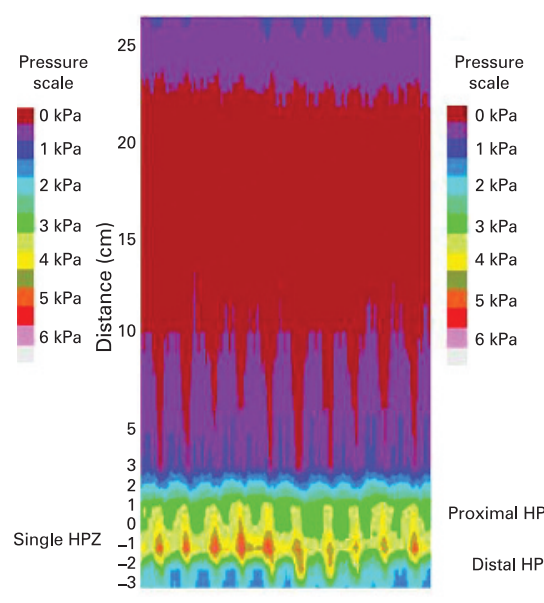

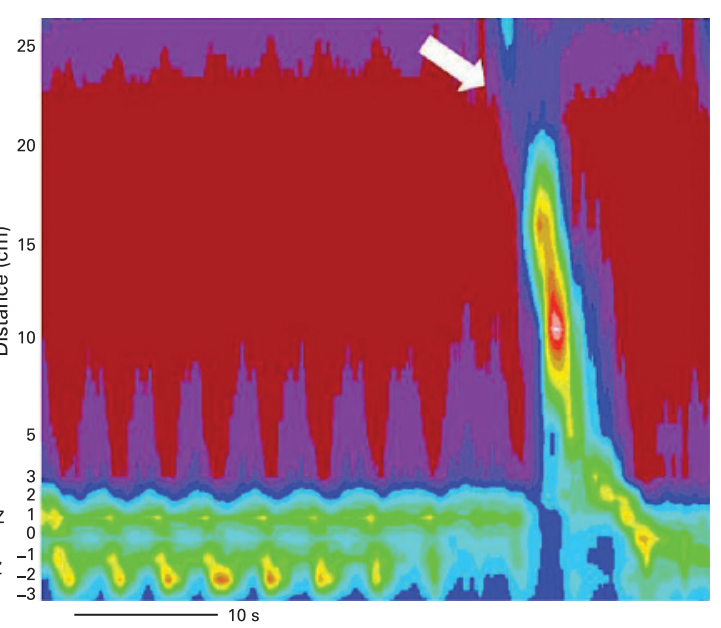

B

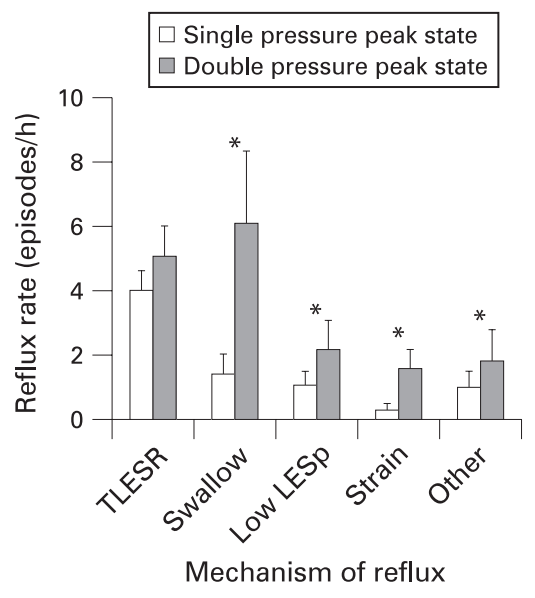

Figure 7 (A) Contour plots of a single and double high-pressure zone configuration. The left panel shows a single pressure peak in the oesophagogastric junction (OGJ). The right panel shows a tracing later during the same recording when the proximal and distal HPZ are spatially separated (a hiatus hernia). Relaxation of both components occurs during a dry swallow (arrow). (Images acquired by 16-channel MMC/Dentsleeve equipment.) (B) Reflux rate (episodes/hour) was much lower during the reduced (single pressure peak) than the unreduced (double pressure peak) state. TLOSRs were the most prevalent reflux mechanism during the reduced state. The increase in reflux rate in the unreduced state was due to other reflux mechanisms. (Reproduced from Bredenoord et al, ${ }^{47}$ with permission.)

tion and mucosal disease have been excluded by endoscopy. If HRM is to be useful in clinical practice it must (1) distinguish abnormal pressure events that disturb function and cause symptoms, from those that have no effect; (2) identify the cause of symptoms in patients in whom conventional investigations are non-diagnostic; and (3) increase diagnostic yield and accuracy.

Despite the limitations of conventional manometry, the first application of HRM to clinical studies in 2000, ${ }^{67}$ was not greeted with universal enthusiasm. An editorialist questioned whether 22 sensors amounted to "a better mousetrap or manometric overkill" and cautioned that technical advances would not necessarily result in clinical advantages. ${ }^{68}$ This debate continues. Formal comparisons of HRM and conventional manometry are open to criticism due to the lack of an independent gold standard. Surrogate measurements of oesophageal function (e.g. bolus transport) do not equate to diagnosis. The use of "final diagnosis at follow-up" to compare the accuracy of investigations is not independent of the investigations performed. Moreover, attempts to demonstrate that HRM guides more effective management are difficult in the absence of safe and effective treatment of dysmotility (e.g. prokinetics). Only two studies have performed direct comparisons between HRM and conventional manometry and, overall, both found that diagnostic agreement was high; ${ }^{867}$ yet the same publications also provided examples of clinically important pathology (box 3) that was detected only by the high-resolution technique, especially in patients with functional, "endoscopy negative" dysphagia. ${ }^{867}$

\section{Evaluation of dysphagia}

HRM is likely to have advantages in the evaluation of pharyngeal dysphagia; however, as yet, only one study has been published. This demonstrated that HRM differentiates between swallowing problems caused by weak or poorly coordinated pharyngeal contraction and the presence of structural pathology, for example hypertrophy of the cricopharyngeal muscle. ${ }^{31}$ Moreover, HRM was able to confirm the functional significance of a "cricopharyngeal bar" on radiology (a common dilemma in clinical practice), by locating the maximum intrabolus pressure gradient at the level of the pathology (fig 4). ${ }^{31}$

Oesophageal dysphagia is the key indication for manometry. Clouse and Staiano published a direct comparison of HRM and conventional manometry (without sleeve sensor) of 212 unselected clinical patients referred for oesophageal investigations. ${ }^{67}$ In this population there was manometric disagreement in $12 \%$ and important diagnostic disagreement in 5\% (10 patients) between HRM and a "limited" five-channel analysis of the same data, chiefly among patients with dysphagia rather than those with reflux symptoms. Compared against "final diagnoses" at 6 months, the limited analysis failed to identify six cases of achalasia and was less effective in segregating hypotensive and aperistaltic motility disorders. The HRM diagnosis was changed at follow-up only in one patient. ${ }^{67}$ The presence of an elevated oesophago-gastric pressure gradient across the LOS had high sensitivity and specificity for achalasia, and was superior to point pressure measurements of LOS relaxation; ${ }^{57}$ however, this study did not compare HRM with sleeve sensor manometry.

A number of recent case reports and clinical studies have assessed the value of HRM in the diagnostic work-up of patients with oesophageal dysphagia, ${ }^{45} 575865676970$ including two larger series presented at DDW 2007. ${ }^{65} 70$ The increased yield of HRM compared to conventional sleeve manometry 
Figure 8 Spatiotemporal plot (top) demonstrates the propagating contractile wavefront (peristalsis) and pressurisation of the bolus domain during a normal water swallow. The dashed black box illustrates the measurement of the contractile or

pressurisation front velocity (PFV) using a $30 \mathrm{~mm} \mathrm{Hg}$ isobaric contour (black line) and the SmartMouse tool in ManoView ${ }^{\mathrm{TM}}$ Analysis software (results in yellow box). The series of spatial pressure variation plots at $0.5 \mathrm{~s}$ intervals (bottom) visualise the intraluminal bolus pressure and pressure gradients. A dashed line indicates the demarcation of the $30 \mathrm{~mm}$ $\mathrm{Hg}$ isobaric contour noted in the spatiotemporal plot while the black dots indicate the locus of luminal closure along the contractile wavefront. The blue arrows thus represent the intra-bolus domain ahead of this wavefront. The integrated relaxation resistance (IRR) expresses the period of time after a swallow that the intrabolus pressure is higher than that in the oesophagogastric junction or stomach and, thus, consistent with effective bolus transport. (Figure courtesy of Pandolfino, Ghosh and colleagues.)
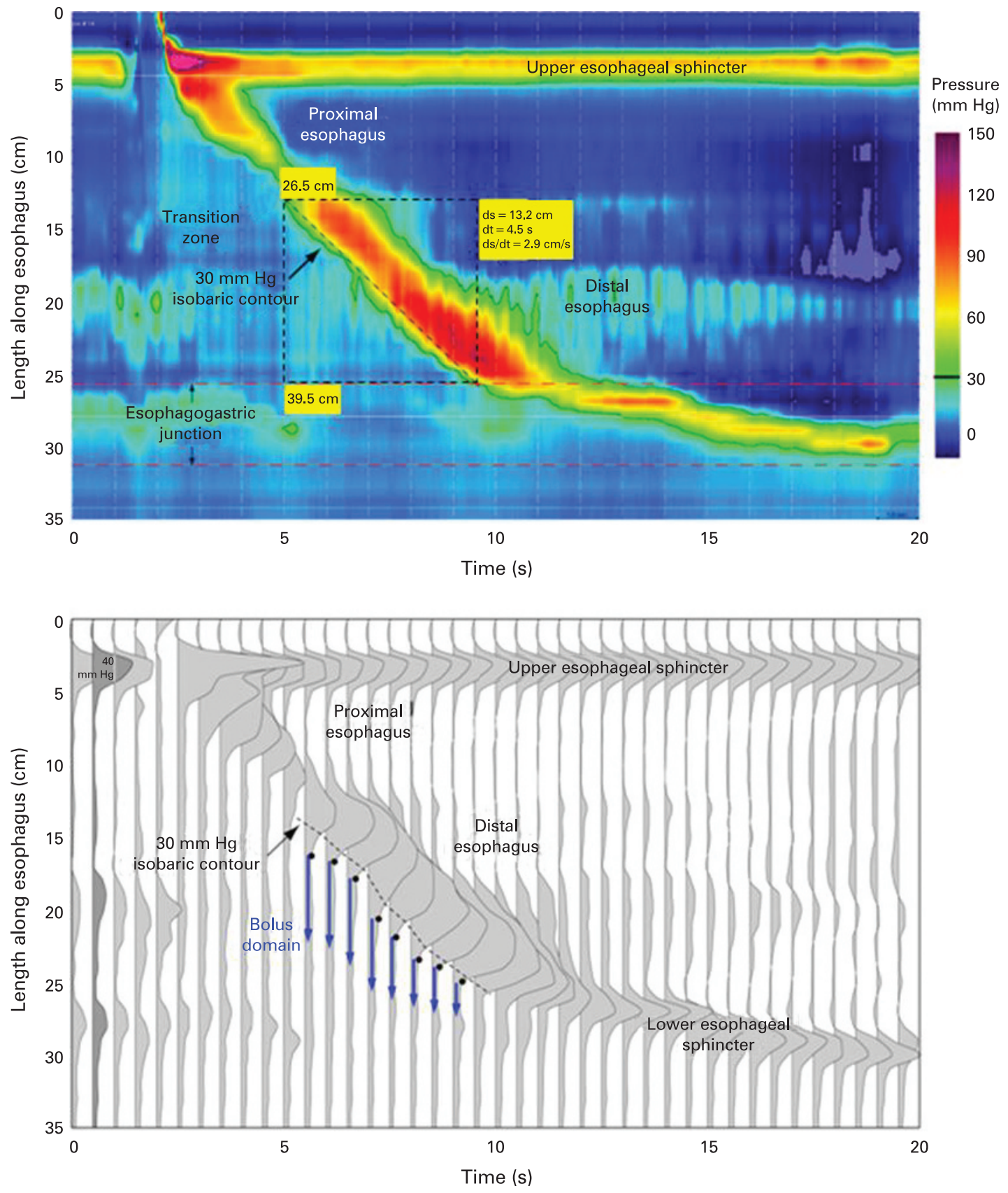

performed by experts was 12-20\% amongst patients with dysphagia referred to specialist centres. Cases that can be identified by HRM but not by conventional manometry include both peristaltic dysmotility and abnormal LOS function. For example, segmental mid-oesophageal dysfunction is not uncommon in patients with chronic bolus impaction (fig 9) and in vigorous achalasia marked oesophageal shortening can draw the LOS above the sleeve sensor resulting in "LOS pseudorelaxation" and misdiagnosis as diffuse oesophageal spasm (fig 10). HRM also helps to distinguish between rapidly propagating contractions ("true

\section{Box 3 HRM in clinical diagnosis}

- Confirms significance of pharyngeal pathology seen on imaging

- Identifies focal peristaltic dysmotility that disturbs bolus clearance

- Increases diagnostic yield and accuracy for achalasia

- Differentiates true oesophageal spasm from rapid elevation of the intra-bolus pressure due to focal dysmotility or obstruction 

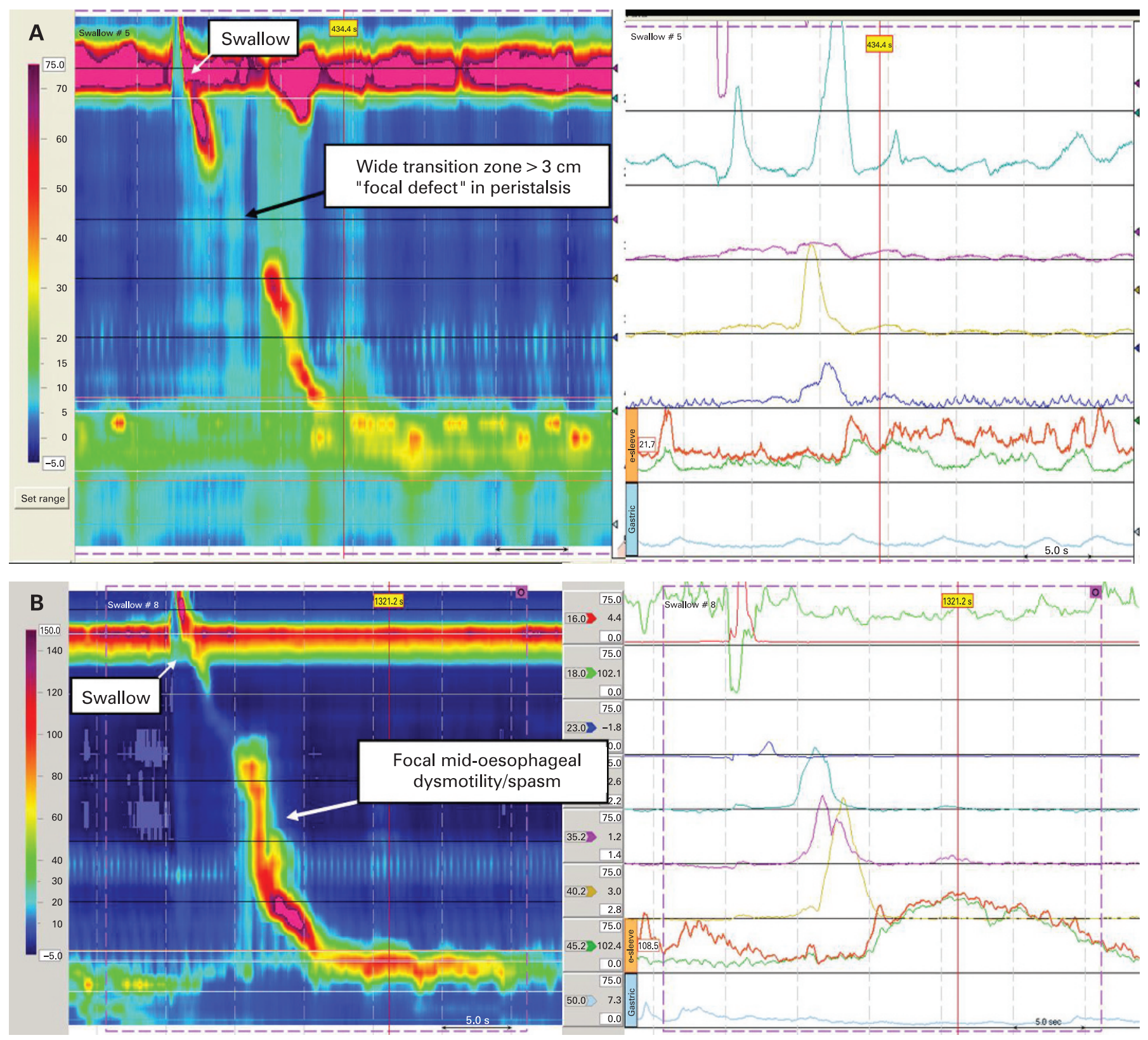

Figure 9 Co-ordination between the proximal and mid-distal compartments of the oesophagus is required for effective bolus transport. (A) The spatiotemporal HRM plot (left) reveals a wide proximal transition zone $(>3 \mathrm{~cm}$, focal aperistalsis) between the proximal and mid-distal oesophagus in a patient with intermittent chest pain and solid bolus escape. Also note increased intra-oesophageal pressure in the upper oesophagus indicative of retained bolus. Contractile pressures are normal and impaired coordination is not appreciated using conventional line plots (right). These findings are common in patients with chronic bolus impaction and also in GORD patients with impaired oesophageal clearance. ${ }^{39}{ }^{40}$ (B) Focal segmental spasm in the mid-oesophagus in a patient with severe, recurrent chest pain and dysphagia. Again, coordination between the proximal and distal compartments of the oesophagus is lost and bolus escape at the level of the aortic arch was seen on concurrent video-fluoroscopy. Dysmotility is restricted to $\sim 3 \mathrm{~cm}$ and conventional manometry was reported as normal elsewhere. (Images acquired by 36-channel SSI Manoscan 360.)

spasm") and rapid, compartmentalised elevation of the intra-bolus pressure due to ineffective contractility or impaired LOS relaxation as seen after fundoplication (fig 11). ${ }^{65}$ Similarly, an elevated intra-bolus pressure gradient within the oesophagus identifies structural pathology, such as extrinsic compression of the oesophagus by tumours (fig 12) or aberrant vasculature. ${ }^{8}$ Measurement of the oesophago-gastric pressure gradient may also be useful in the assessment of persistent or recurrent symptoms after anti-reflux surgery and management of achalasia. A report of 100 consecutive patients with endoscopy-negative dysphagia referred to a tertiary referral centre suggested that 1 in 5 patients received a diagnosis by HRM which would not have been established or fully appreciated using conventional manometry (a similar proportion had no diagnosis even with HRM). ${ }^{70}$ Although it cannot be proven in all cases that these findings provide a definitive explanation 
Figure 10 Vigorous achalasia with pseudorelaxation of the LOS in a patient with dysphagia, regurgitation and chest pain on swallowing. There is incomplete LOS relaxation and spasm diagnostic of vigorous achalasia; however, there is also marked shortening of the oesophageal body (spasm of the longitudinal muscle layer). This causes pseudo-relaxation of the LOS on the $6 \mathrm{~cm}$ e-sleeve recording (below) due to relative movement of the catheter and the sphincter, as the LOS moves into the chest. Extending the limits of the e-sleeve to $10 \mathrm{~cm}$ would resolve pseudorelaxation (not possible with conventional sleeve sensors). This patient was diagnosed with diffuse oesophageal spasm by conventional manometry elsewhere. (Reproduced from Fox et al, ${ }^{8}$ with permission.)

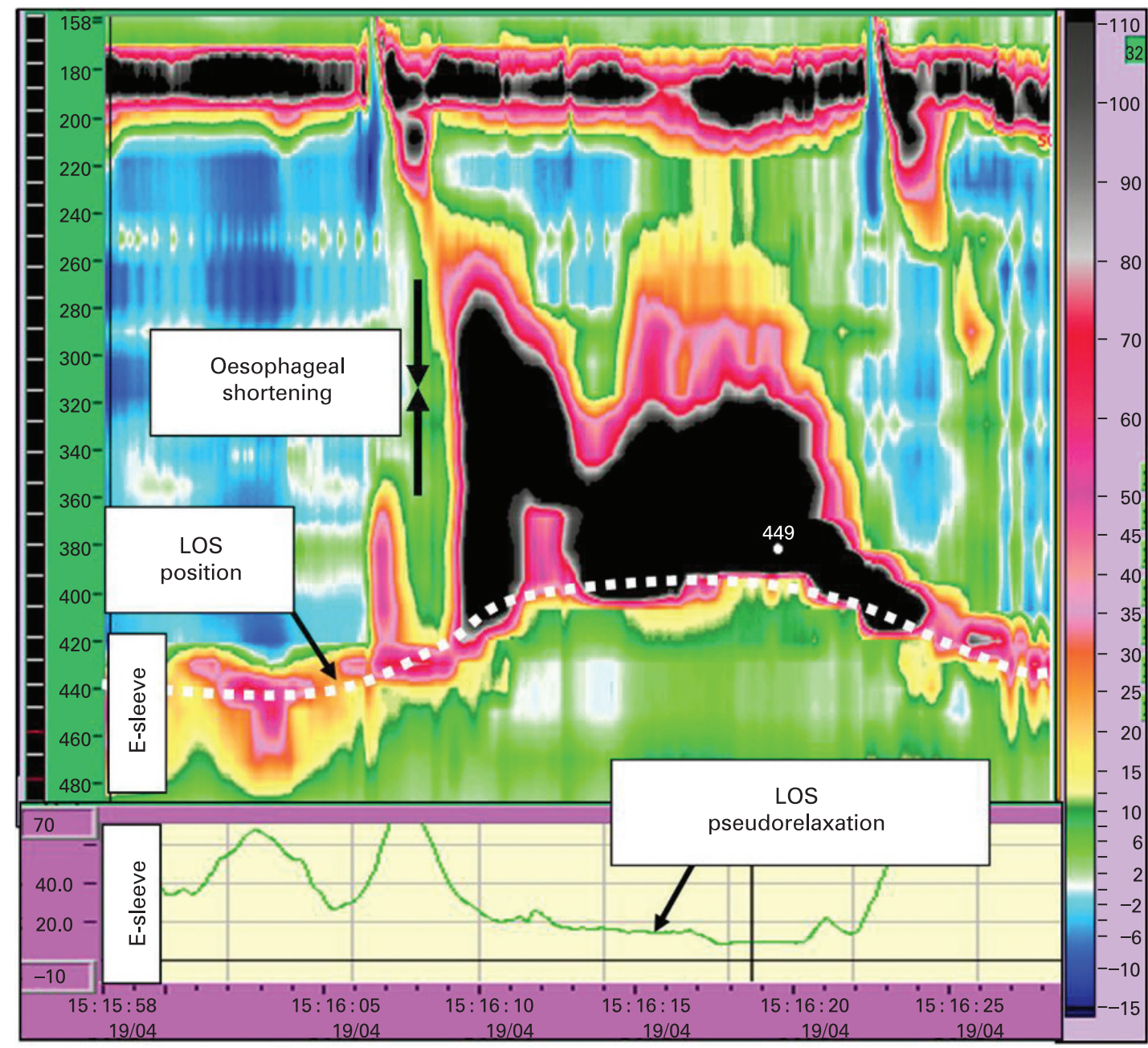

for symptoms, in some patients typical symptoms were seen to occur at the same time as dysmotility or elevated intra-bolus pressure.

\section{Unexplained (non-cardiac) chest pain}

Oesophageal manometry has a role in the evaluation of patients with unexplained (non-cardiac) chest pain; however, it should not be an initial test for this symptom. Cardiac and musculoskeletal causes of chest pain should be excluded and endoscopy performed to rule out mucosal evidence of GORD. ${ }^{71}$ In patients with non-cardiac chest pain, the chance of finding achalasia or oesophageal spasm is low. ${ }^{72}$ In contrast, non-specific, hypertensive oesophageal contractions (>180 mm $\mathrm{Hg}$ ) are often found although the relationship between chest pain and these abnormalities is weak until the contractile amplitudes are much higher. ${ }^{73}$ Similar to conventional studies, HRM has shown that patients with a clear link between oesophageal motor abnormalities and chest pain usually have high-pressure amplitudes, and prolonged and repetitive contractions in the distal oesophagus. ${ }^{41}{ }^{65}$ Occasionally, as reported by endoscopic ultrasound, ${ }^{74}$ oesophageal shortening due to longitudinal muscle spasm is detected by HRM during episodes of chest pain (fig 13).

\section{Placement of the $\mathrm{pH}$ sensor for ambulatory oesophageal $\mathrm{pH}$ monitoring}

Although GORD is not an indication for oesophageal manometry, it is performed prior to ambulatory reflux studies to place the $\mathrm{pH}$ sensor $5 \mathrm{~cm}$ proximal to the upper border of the LOS. Manometry is the single most accurate and reproducible method for achieving this. ${ }^{72}$ HRM facilitates identification of the LOS, removes the need for a time-consuming pull-through procedure and significantly improves the accuracy of placement compared to conventional manometry, especially in the presence of weak, unstable LOS or a hiatus hernia (fig 14). ${ }^{67}$

\section{Evaluation prior to anti-reflux surgery}

Anti-reflux surgery is effective in reducing oesophageal acid exposure and reflux symptoms but occasionally severe, persistent dysphagia occurs post-operatively. ${ }^{75-77}$ Symptoms such as the inability to belch and the gas-bloat syndrome may also occur. Oesophageal manometry is an accepted part 

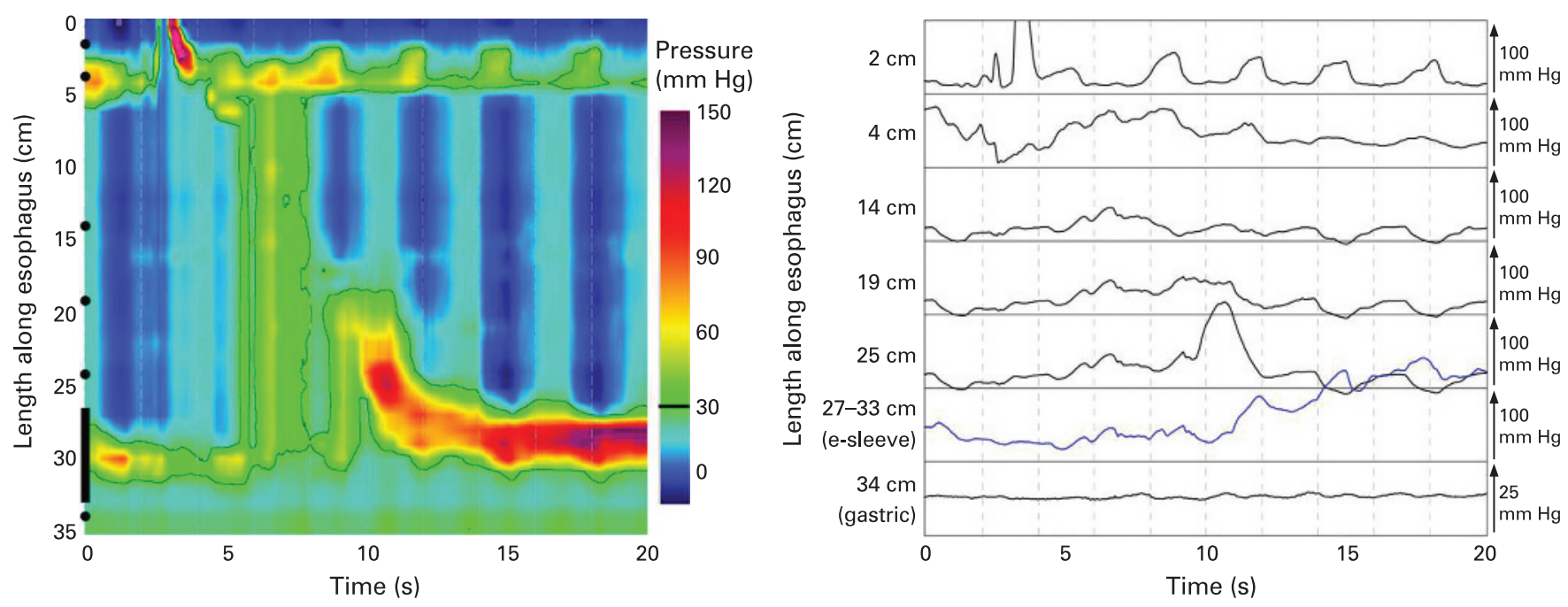

Figure 11 Spatiotemporal plot illustrates functional obstruction in a patient post fundoplication. There is rapid elevation of the intra-bolus pressure (pressurisation front velocity $>8 \mathrm{~cm} / \mathrm{s}$ ) with pan-oesophageal pressurisation ( $>15 \mathrm{~mm} \mathrm{Hg}$ ) on swallowing. This compartmentalised pressurisation is due to increased resistance to flow at the level of the fundoplication wrap (i.e. functional obstruction). This is difficult to appreciate using conventional pressure tracings in which these effects are often attributed to "low pressure spasm" and incomplete LOS relaxation. (Figure courtesy of Pandolfino, Ghosh and colleagues.)

of the pre-operative evaluation of patients undergoing anti-reflux surgery. ${ }^{11}{ }^{13}$ Intuitively, this approach makes sense because the surgeon augments the anti-reflux barrier with the fundoplication, increasing the risk for impaired bolus transport. On the other hand, non-specific dysmotility may resolve after anti-reflux surgery. Although it has been shown that abnormal bolus transit on pre-operative assessment predicts postoperative dysphagia, ${ }^{78}$ other studies indicate that conventional manometric evaluation does not predict postoperative dysphagia. ${ }^{78-82}$ Thus, current evidence suggests that oesophageal dysmotility does not require tailoring of surgical management. It should be noted, however, that these studies excluded subjects with severe peristaltic dysfunction and, therefore, one should be cautious to extrapolate their recommendations to all surgical candidates. Ongoing studies will assess whether the increased ability of HRM to detect oesophageal dysmotility that impairs bolus transport will improve the prediction of postoperative dysphagia.

Recent HRM studies have shown that after Nissen fundoplication separation of LOS and

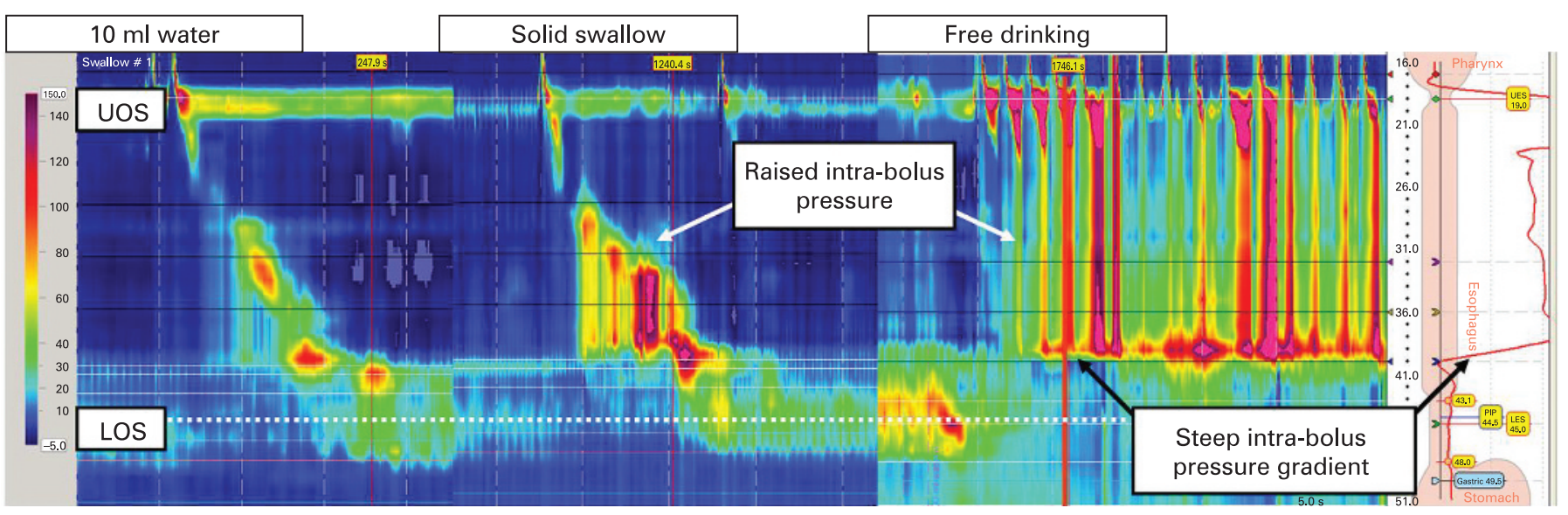

Figure 12 Investigation of progressive dysphagia in a patient with long-standing reflux symptoms. Endoscopy and biopsies had revealed Barrett's oesophagus without dysplastic change. Computed tomography was unremarkable. LOS pressure was low and unstable. On $10 \mathrm{ml}$ water swallow, peristalsis was weak and the pressure of the peristaltic wavefront was not maintained above $30 \mathrm{~mm} \mathrm{Hg}$ (i.e. "non-specific" motor dysfunction typical in severe GORD). On solid swallows, rapid elevation of intra-bolus pressure (compartmentalised beneath the peristaltic wave and a position $6 \mathrm{~cm}$ above the LOS) was observed. Following this, intra-bolus pressure also rose rapidly during free drinking. The steep pressure gradient $6 \mathrm{~cm}$ above the LOS indicates the presence of structural resistance to solid bolus transport at this level. Small volumes of fluid passed relatively freely; however, solids obstructed passage. Endoscopic ultrasound demonstrated extrinsic compression of the oesophagus by a tumour. Trans-oesophageal biopsy revealed oesophageal adenocarcinoma. 


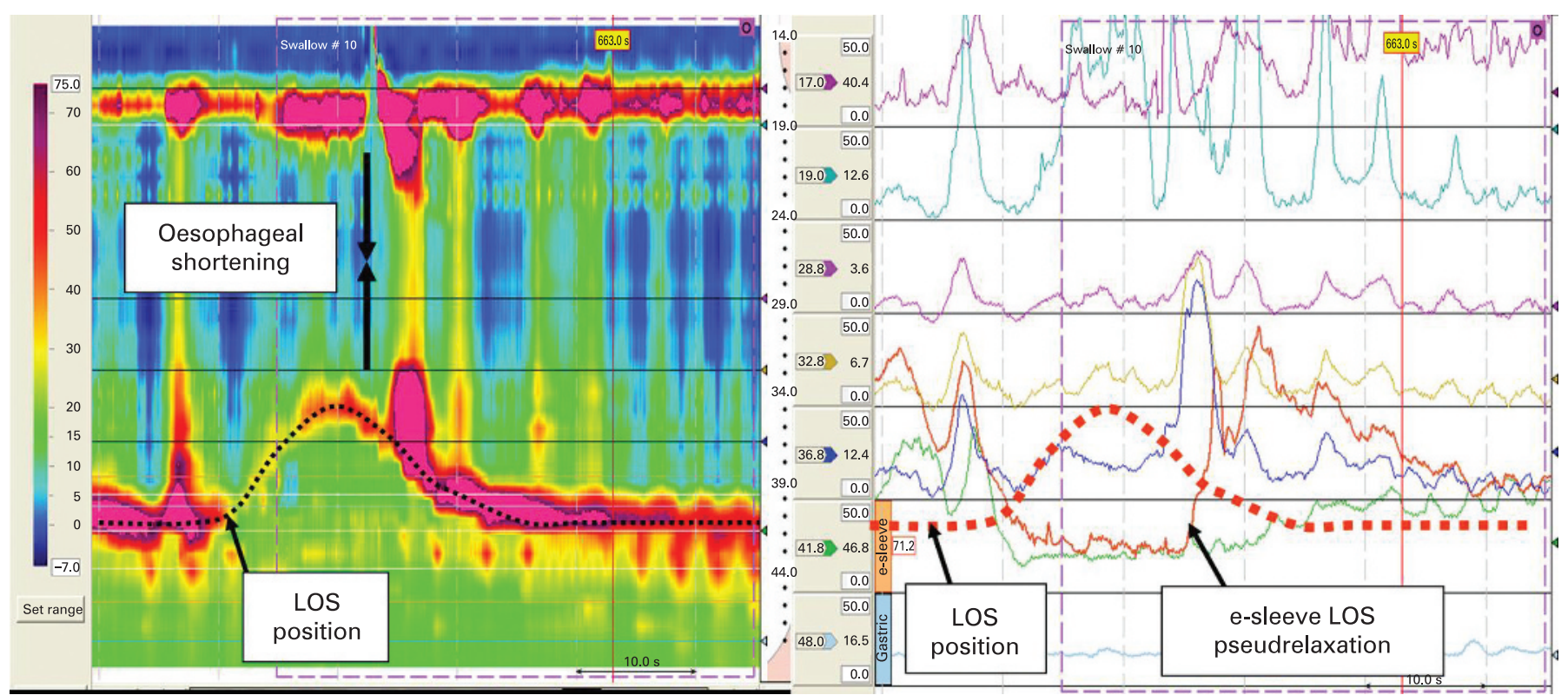

Figure 13 Spasm of the longitudinal muscle layer with oesophageal shortening was observed concurrent with symptoms in a patient complaining of intermittent chest pain. The LOS does not relax during this event and is seen to rise into the chest (LOS relaxation on water swallows was normal). Also note pseudo-relaxation of the LOS on the e-sleeve recording (bold brown line plot, right panel) due to relative movement of the catheter and the sphincter. Longitudinal shortening was not appreciated on conventional manometry.

diaphragm as seen prior to the operation does not occur, $^{83}$ and a higher LOS nadir pressure during TLOSRs is often present. ${ }^{51}$ However, symptoms such as dysphagia and the inability to belch were not related to these changes, thus the value of HRM prior to anti-reflux surgery remains uncertain.

\section{TOWARDS A NEW CLASSIFICATION OF OESOPHAGEAL DYSMOTILITY}

Current classification systems provide a definitive diagnosis only in achalasia and severe, diffuse oesophageal spasm, ${ }^{59}$ with other abnormalities labelled as "non-specific oesophageal motor disorders" because their clinical relevance remains

Figure 14 Placement of $\mathrm{pH}$ sensors for reflux studies is facilitated by spatiotemporal plots that clearly reveal the LOS position, especially if this is only seen during post-deglutative contraction. (Images acquired by 32-channel AMS/Dentsleeve equipment.) Here, in the presence of a large hiatus hernia, accurate positioning based on conventional manometry would have been difficult and up to $4 \mathrm{~cm}$ too distal compared to positioning based on HRM. 
uncertain. ${ }^{12}$ With intraluminal impedance monitoring it can be clarified whether oesophageal dysmotility is consistent with bolus transport, but not the mechanism by which this occurs.

A new classification of oesophageal dysmotility based on HRM has been proposed by the Chicago group based on a systematic analysis of 400 patients referred for oesophageal investigations and 75 controls (table 2). Individual water swallows are analysed in a systematic, stepwise manner considering (1) oesophago-gastric junction relaxation; (2) the presence and propagation of oesophageal peristalsis and/or the build-up of intra-bolus pressure within the oesophagus; and (3) contractile vigour. The resultant scheme is accessible to those familiar with conventional manometry, but takes advantage of the high-resolution pressure data and spatiotemporal analysis to detect segmental oesophageal dysmotility and provide an assessment of the functional significance of these findings. This system applies objective criteria to the assessment of hypo- and hyper-contractile dysmotility and removes the category of "non-specific motor disorders". It also distinguishes oesophageal spasm from rapid elevation of the intra-bolus pressure due to ineffective contractility or impaired LOS relaxation, a common source of diagnostic disagreement in the past. ${ }^{65}$

The "Chicago Classification" is a working document and its validity (e.g. the division between hypo- and hyper-contractile dysmotility) must be tested by future studies. Nevertheless, it represents a starting point for practitioners to discuss the approach to and interpretation of HRM findings. Agreement on a standardised "data set" to be acquired and reported by HRM would provide a solid basis on which the technique could be studied (box 4). This process has begun with the publication of normal ranges for peristaltic and sphincteric motor function by solid state HRM; 282963 with similar results obtained by a water perfused system. ${ }^{40}$ As experience grows, the appropriate place of HRM and other new technology (e.g. impedance monitoring) in the clinical work-up of patients will become apparent. These are important goals if these technological advances are to fulfil their early promise to patients presenting with oesophageal symptoms.

\section{PRACTICAL ADVANTAGES OF HRM IN CLINICAL PRACTICE}

Although water-perfused HRM has been available for some years, rapid uptake of HRM has begun only since the introduction of a commercially available solid-state system. Thus, almost irrespective of the evidence, it appears to be the practical advantages of this technology that have brought wide-spread acceptance of the technique. HRM removes the need for a pull-through procedure, reduces the time required for the procedure and facilitates placement of $\mathrm{pH}$ sensors (if required). These features ensure that HRM can be performed by relatively inexperienced staff without compromising the quality of the study. Moreover, new users prefer the spatio- temporal display of pressure information, find it significantly easier to interpret and increase their accuracy of diagnosis compared to conventional line plots (Gruebel and Hebbard, unpublished data); advantages that are likely due to the fact that the human brain is more attuned to recognise patterns in complex images than to interpret complex abstract information. Commercial packages provide both a rapid, semi-automatic analysis of test swallows and applications that allow detailed interrogation of the pressure data. This approach combines the speed of pattern recognition with the rigorous assessment of the objective pressure measurements as appropriate. Indeed, the ability to acquire and analyse good quality pressure measurements quickly and easily is valuable in itself. Many centres continue to perform manometry using "less than optimal" technology with the measurements acquired by inexperienced staff. In such situations, additional to picking up cases that would have been missed under any circumstances, HRM will raise the overall standard of oesophageal investigation. In addition, HRM provides a more definitive explanation for symptoms that can be communicated and demonstrated to patients using the colourful spatiotemporal plots; a process that is often therapeutic in itself.

\section{Limitations of high-resolution manometry}

Some concern has been expressed at the safety implications of multiple use nasogastric catheters; ${ }^{84}$ however, reports of disease transmitted by manometry are extremely rare and disposable sheaths are available for at least one solid-state HRM catheter. Expense is an important limitation of HRM compared to conventional manometry and, in the absence of outcome studies, the costeffectiveness of this procedure cannot be assessed. Increased throughput of patients may offset initial costs in busy units and existing data appear to support its use in tertiary referral units; however, it remains to be shown that HRM provides sufficient benefit in all settings. In addition, it is important to state that not every "abnormality" of pressure activity is linked to oesophageal dysfunction or symptoms, and not all patients with functional, "endoscopy-negative" dysphagia (or other symptoms) receive a definitive diagnosis on HRM. ${ }^{70}$ Over-enthusiastic interpretation of HRM could lead to unnecessary and ineffective treatment.

\section{FUTURE DIRECTIONS OF OESOPHAGEAL HRM}

HRM provides a vivid and detailed display of oesophageal pathophysiology; however, this alone is not enough to influence patient management. With regards to diagnosis, most patients do not experience oesophageal symptoms with single swallows of water, but rather during and after a meal; however, interpreting this complex data is difficult with conventional manometry. ${ }^{85} 86$ As shown in some of the clinical cases, HRM makes it possible to extract meaningful information from physiological challenges (e.g. multiple swallows, test meal). With 
Table 2 Classification of oesophageal motor abnormalities for high-resolution manometry (adapted: original courtesy of John Pandolfino, Sudip Ghosh and Peter Kahrilas)

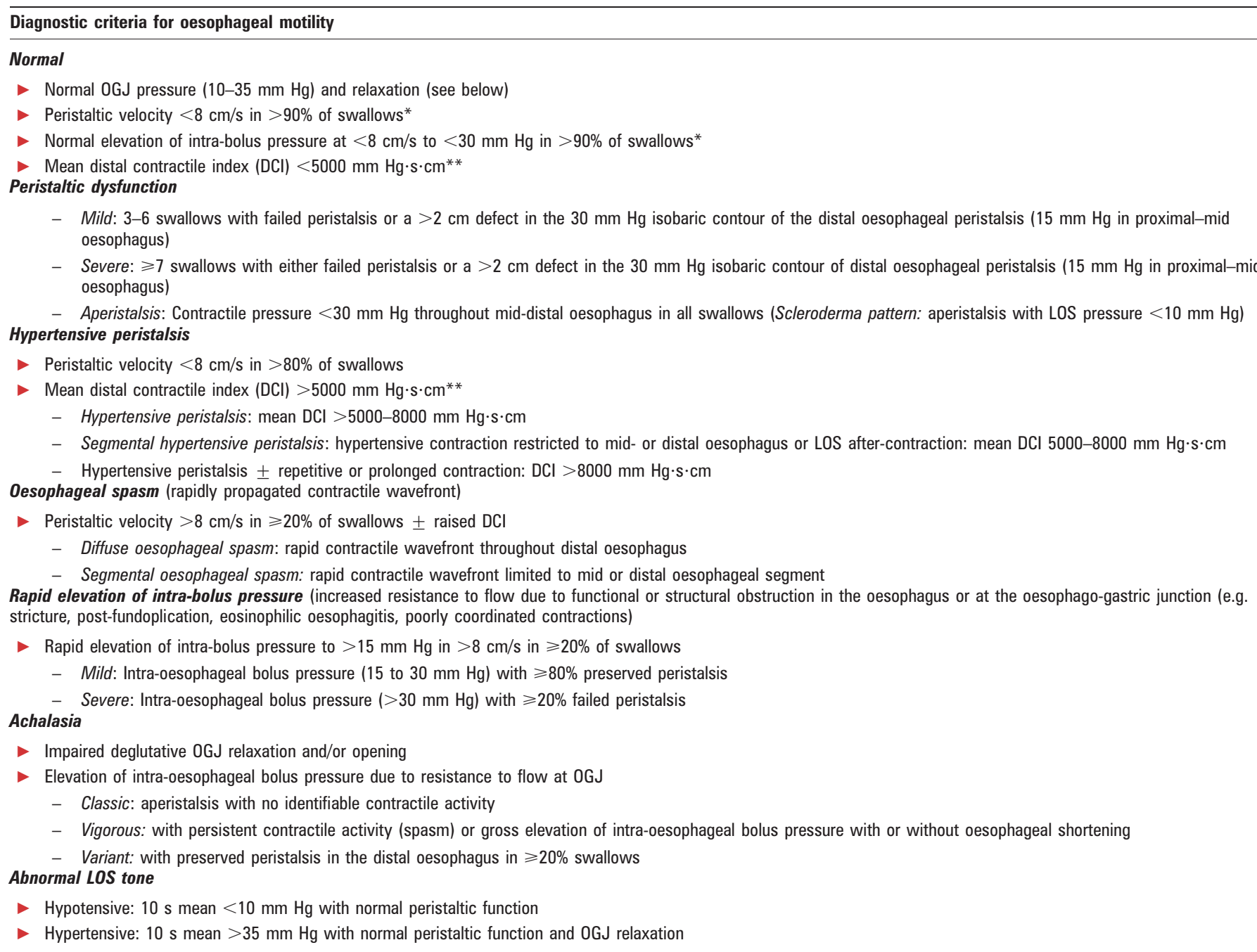

*In the original, the pressurisation front velocity (PFV) incorporated both rapidly propagated contractile wavefront (i.e. spasm) and also rapidly rising intra-bolus pressure (indicating increased resistance to flow).

${ }^{* *}$ Distal contractile integral (or "contractile volume") is pressure $\times$ duration $\times$ length of contraction in the smooth muscle oesophagus. With SSI equipment, the distal contractile integral is calculated by the Smart Mouse tool in ManoView ${ }^{\text {TM }}$ by outlining a space-time box that encompasses the distal peristaltic wave, from the transition zone to the proximal EGJ at the end of peristalsis or at $15 \mathrm{~s}$ if no peristaltic wave is noted. The distal contractile integral can then be calculated by multiplying the mean pressure in the space-time box by the length and duration of the space-time box. If this is not available then a peak contractile pressure of $180 \mathrm{~mm} \mathrm{Hg}$ and $260 \mathrm{~mm} \mathrm{Hg}$ ( + repetitive contractions) should be taken for DCI 5000 and $8000 \mathrm{~mm} \mathrm{Hg} \cdot \mathrm{s} \cdot \mathrm{cm}$ respectively.

regards to treatment, as new medications with actions on oesophageal motor activity are developed, preliminary studies suggest that HRM may identify specific dysmotility that responds to specific pharmacological intervention. For example, symptomatic focal spasm was shown to respond to sildenafili, ${ }^{45}$ and chronic bolus escape due to weak mid-oesophageal contractility was reduced by tegaserod. ${ }^{40}$ Similarly for surgical management, early experience suggests that HRM can identify whether persistent or recurrent symptoms after anti-reflux and achalasia surgery are due to persistent dysmotility in the oesophageal body or functional obstruction at the level of the oesophago-gastric junction (fig 15). These encouraging observations suggest clinical usefulness of HRM in identifying abnormalities of oesophageal function that respond to targeted medical and surgical management.
Technical advances in the field of oesophageal pressure measurement continue. A combined HRM/impedance catheter is in an advanced state of development, and "high-definition manometry" with spatial resolution of approaching $1 \mathrm{~mm}$ and sensitivity to the radial distribution of pressure was presented at DDW 2007. Perhaps most appealing of all, should ambulatory HRM become a reality, it would improve the ability to associate dysmotility and symptoms (as for reflux studies).

Beyond the oesophagus, HRM makes it easy to localise the pylorus and obtain stable gastro-duodenal measurements without the use of trans-membrane potential difference monitoring. ${ }^{87}$ HRM remains insensitive to non-occlusive gastric contractions ${ }^{88}$ however, the assessment of pyloric pressure and antro-pyloric pressure gradient have already 

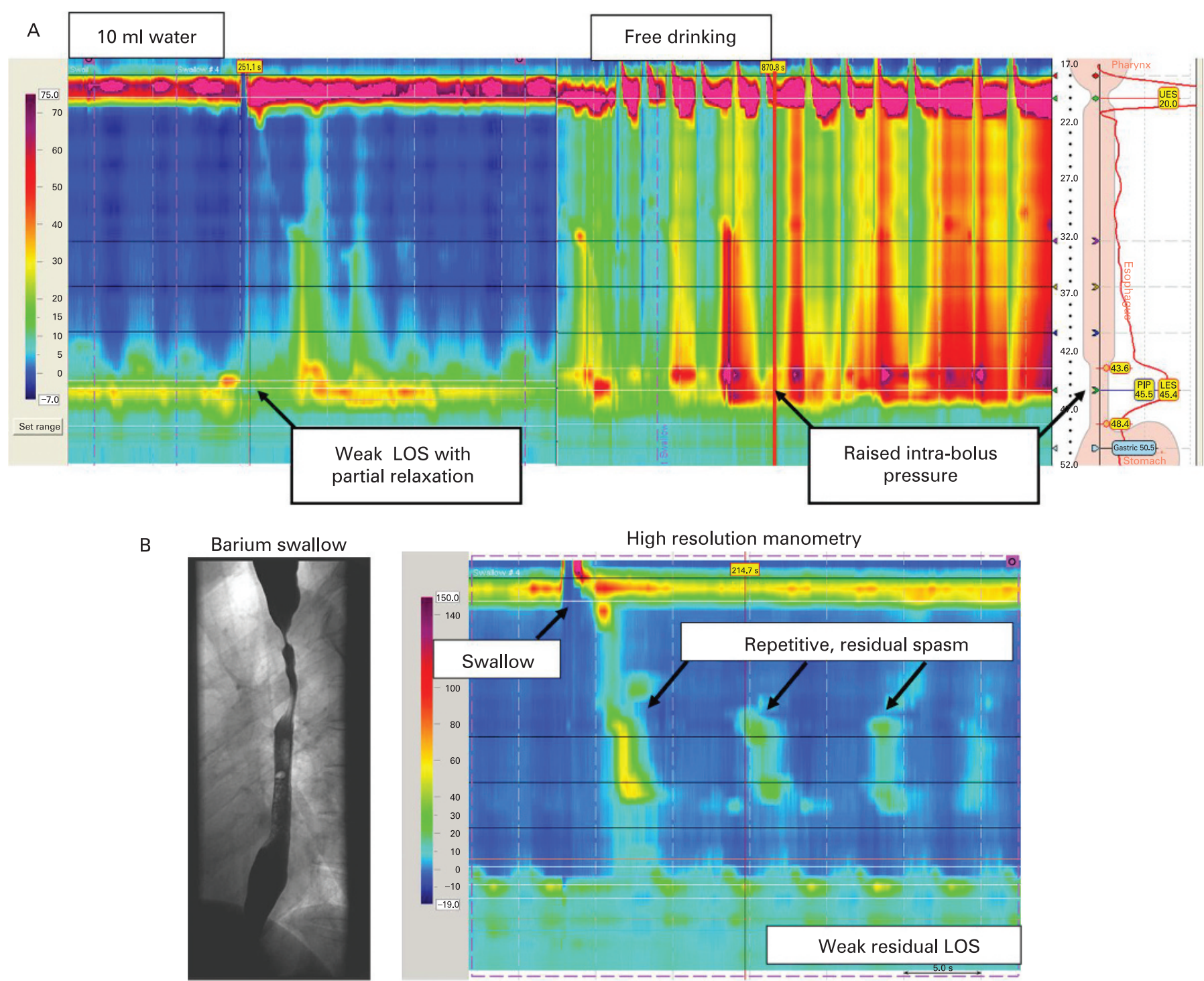

Figure 15 (A) Investigation of persistent dysphagia in a patient with achalasia after Heller's myotomy. Resting LOS pressure is relatively low with partial relaxation apparent on the $10 \mathrm{ml}$ water swallow; however, the intra-bolus (intra-oesophageal) pressure rises rapidly during repeated water swallows. This indicates that fluid is building up within the oesophageal cavity due to impaired LOS relaxation and opening. The sharp drop of intrabolus pressure gradient at the level of the oesophago-gastric junction confirms the functional significance of this observation. The patient improved with LOS dilation. (B) Investigation of persistent dysphagia in a patient with vigorous achalasia following Heller's myotomy with extension into the oesophageal body. Endoscopy was unremarkable. Video-fluoroscopy (left) showed retention of bolus in the proximal and distal oesophagus with tertiary contractions. On HRM, resting LOS pressure was essentially absent but persistent spasm was observed above the level of the myotomy. In such cases HRM guides application of botulinum toxin or further surgical management enabling the effective management of persistent dysmotility. (Figure courtesy of Lam and Botha, St Thomas' Hospital, London, UK.)

\section{Box 4 Recommended study protocol for HRM studies}

- Baseline recording of LOS pressure (after minimum 5 min habituation)

-Water swallows (e.g. $10 \times 10 \mathrm{ml}$ ) separated by minimum $20 \mathrm{~s}$ (larger volumes increase sensitivity for pharyngeal dysfunction)

- Multiple rapid swallow of $>100 \mathrm{ml}$ water (free drinking increases sensitivity to LOS dysfunction and other causes of functional or structural obstruction)

- Consider solid bolus if symptoms intermittent and triggered by solid food (increases diagnostic sensitivity and clinical significance of manometric findings)

- Consider test meal if postprandial symptoms prominent (assess pressure and stability of reflux barrier, reflux episodes and rumination) provided important insights into the mechanism of gastric emptying. ${ }^{89} \mathrm{HRM}$ also facilitates the acquisition of anorectal measurements. ${ }^{90}$

\section{CONCLUSIONS}

High-resolution manometry is an advance in intraluminal pressure measurement that meets the standards required of a useful oesophageal investigation. Closely spaced sensors describe the complex functional anatomy of the oesophagus and its sphincters. More fundamentally, HRM spatiotemporal plots describe the forces that drive food and fluid through the oesophagus and 
determine when gastro-oesophageal reflux can occur.

HRM has improved our understanding of how oesophageal dysmotility impairs function and causes symptoms; however, the value of HRM in clinical practice has yet to be fully established. There is growing evidence that HRM identifies clinically relevant abnormalities not detected by conventional manometry and increases diagnostic accuracy, especially in cases of functional, "endoscopy negative" dysphagia. Moreover, the practical advantages of HRM will improve the quality of oesophageal studies in "everyday" practice. Should HRM establish itself as the new standard of oesophageal pressure measurement, it is certain that a new classification of oesophageal disorders will be required. Indeed, this process has already begun and will define the place of HRM in patient management. Looking ahead, HRM is an excellent tool to describe oesophageal pathophysiology and, as new medications and procedures with specific effects on oesophageal function are developed, HRM may identify patients who will benefit from these treatments.

Acknowledgements: Mark Fox thanks Werner Schwizer, James Brasseur and Geoff Hebbard for their advice and insight into oesophageal physiology and clinical measurement. Albert Bredenoord acknowledges helpful comments and insights provided by André Smout.

Funding: M.R.F. is a member of the Zürich Human Integrated Physiology (ZHIP) Group of Zürich University and is supported by the Swiss National Fund for Medical Research and an unrestricted research grant from AstraZeneca, Mölndal, Sweden.

Competing interests: M.R.F. has been paid by Synectics (European distributors for Sierra Scientific Instruments, manufacturers of the ManoScan 360 HRM system), and Oakfield (European distributors for Advanced Manometry Systems: manufacturers of a water-perfused HRM system), to attend and speak at educational/training events. A.J.B. has been paid by Medical Measurement Systems (MMS: manufacturers of a water-perfused HRM system) to attend and speak at an educational event. There are no other competing interests.

Dedication: This review is dedicated to Dr Ray E Clouse, a founding father of high-resolution manometry, who died 31 August 2007.

\section{REFERENCES}

1. Brasseur JG. A fluid mechanical perspective on esophageal bolus transport. Dysphagia 1987;2:32-9.

2. Brasseur JG, Dodds WJ. Interpretation of intraluminal manometric measurements in terms of swallowing mechanics. Dysphagia 1991:6:100-19.

3. Fyke FE, Code CF, Schlegel JF. The gastroesophageal sphincter in healthy human beings. Gastroenterologia (Basel) 1956;86:135-50.

4. Dent J. Approaches to driving the evolving understanding of lower oesophageal sphincter mechanical function. J Smooth Muscle Res 2007:43:1-14.

5. Dent J. A new technique for continuous sphincter pressure measurement. Gastroenterology 1976;71:263-7.

6. Dent J, Holloway RH, Toouli J, et al. Mechanisms of lower oesophageal sphincter incompetence in patients with symptomatic gastrooesophageal reflux. Gut 1988;29:1020-8.

7. Shi G, Ergun GA, Manka M, et al. Lower esophageal sphincter relaxation characteristics using a sleeve sensor in clinical manometry. Am J Gastroenterol 1998;93:2373-9.

8. Fox M, Hebbard G, Janiak P, et al. High-resolution manometry predicts the success of oesophageal bolus transport and identifies clinically important abnormalities not detected by conventional manometry. Neurogastroenterol Motil 2004;16:533-42.

9. Mittal RK, Holloway RH, Penagini R, et al. Transient lower esophageal sphincter relaxation. Gastroenterology 1995;109:60110.
10. Pandolfino JE, Kahrilas PJ. American Gastroenterological Association medical position statement: Clinical use of esophageal manometry. Gastroenterology 2005;128:207-8.

11. Bodger K, Trudgill N. Guidelines for oesophageal manometry and pH monitoring. BSG Guidelines, 2006. http://www.bsg.org.uk/ pdf word docs/oesp man.pdf (accessed 28 December 2007).

12. Spechler SJ, Castell DO. Classification of oesophageal motility abnormalities. Gut 2001;49:145-51.

13. Pandolfino JE, Kahrilas PJ. AGA technical review on the clinical use of esophageal manometry. Gastroenterology 2005;128:20924.

14. Nayar DS, Khandwala F, Achkar E, et al. Esophageal manometry: assessment of interpreter consistency. Clin Gastroenterol Hepatol 2005; 3:218-24.

15. Reidel WL, Clouse RE. Variations in clinical presentation of patients with esophageal contraction abnormalities. Dig Dis Sci 1985; 30:1065-71

16. Achem SR, Crittenden J, Kolts B, et al. Long-term clinical and manometric follow-up of patients with nonspecific esophageal motor disorders. Am J Gastroenterol 1992;87:825-30.

17. Swift GL, Alban-Davies H, McKirdy H, et al. A long-term clinical review of patients with oesophageal pain. $0 \mathrm{~J}$ Med 1991;81:93744.

18. Kahrilas PJ, Clouse RE, Hogan WL. American Gastroenterological Association technical review on the use of esophageal manometry. Gastroenterology 1994;107:1865-84.

19. Ott DJ, Richter JE, Chen YM, et al. Esophageal radiography and manometry: correlation in 172 patients with dysphagia. AJR Am J Roentgenol 1987;149:307-11.

20. Lundquist A, Olsson R, Ekberg 0. Clinical and radiologic evaluation reveals high prevalence of abnormalities in young adults with dysphagia. Dysphagia 1998;13:202-7.

21. Clouse R, Staiano A. Topography of the esophageal peristaltic pressure wave. Am J Physiol Gastrointest Liver Physiol 1991;261:G677-84.

22. Clouse RE, Staiano A. Topography of normal and high-amplitude esophageal peristalsis. Am J Physiol 1993;265(6 Pt 1):G1098-107.

23. Staiano A, Clouse RE. The effects of cisapride on the topography of oesophageal peristalsis. Aliment Pharmacol Ther 1996;10:87582.

24. Kahrilas PJ, Lin S, Chen J, et al. The effect of hiatus hernia on gastro-oesophageal junction pressure [see comments]. Gut 1999;44:476-82.

25. Omari T, Bakewell M, Fraser R, et al. Intraluminal micromanometry: an evaluation of the dynamic performance of micro-extrusions and sleeve sensors. Neurogastroenterol Motil 1996;8:241-5.

26. Chen WH, Omari TI, Holloway RH, et al. A comparison of micromanometric and standard manometric techniques for recording of oesophageal motility. Neurogastroenterol Motil 1998;10:253-62.

27. Clouse RE, Parks T, Haroian LR, et al. Development and clinical validation of a solid-state high-resolution pressure measurement system for simplified and consistent esophageal manometry. Am J Gastroenterol 2003;98:S32-3.

28. Pandolfino JE, Shi G, Zhang 0, et al. Measuring EGJ opening patterns using high resolution intraluminal impedance. Neurogastroenterol Motil 2005;17:200-6.

29. Ghosh SK, Pandolfino JE, Zhang 0, et al. Quantifying esophageal peristalsis with high-resolution manometry: a study of 75 asymptomatic volunteers. Am J Physiol Gastrointest Liver Physiol 2006;290:G988-97.

30. Williams R, Pal A, Brasseur JG, et al. Space-time pressure structure of the pharyngo-esophageal segment during swallowing Am J Physiol 2001;281:G1290-300.

31. Pal A, Williams RB, Cook IJ, et al. Intrabolus pressure gradient identifies pathological constriction in the upper esophageal sphincter during flow. Am J Physiol Gastrointest Liver Physiol 2003;285:G1037-48.

32. Goyal RK, Gidda JS. Relation between electrical and mechanical activity in esophageal smooth muscle. Am J Physiol 1981;240:G305-11.

33. Sugarbaker DJ, Rattan S, Goyal RK. Mechanical and electrical activity of esophageal smooth muscle during peristalsis. Am J Physiol 1984;246(2 Pt 1):G145-50.

34. Sifrim D, Janssens J, Vantrappen G. A wave of inhibition precedes primary peristaltic contractions in the human esophagus. Gastroenterology 1992;103:876-82.

35. Kahrilas PJ, Dodds WJ, Hogan WJ, et al. Esophageal peristaltic dysfunction in peptic esophagitis. Gastroenterology 1986;91:897904. 
36. Kahrilas PJ, Dodds WJ, Hogan WJ. Effect of peristaltic dysfunction on esophageal volume clearance. Gastroenterology 1988;94:73-80.

37. Li M, Brasseur JG, Dodds WJ. Analyses of normal and abnormal esophageal transport using computer simulations. Am J Physiol 1994;266(4 Pt 1):G525-43.

38. Ghosh SK, Janiak P, Schwizer W, et al. Physiology of the esophageal pressure transition zone: separate contraction waves above and below. Am J Physiol Gastrointest Liver Physio 2006;290:G568-76.

39. Ghosh SK, Janiak P, Fox M, et al. Physiology of the esophageal transition zone in the presence of chronic bolus retention: studies using concurrent high resolution manometry and digital fluoroscopy. Neurogastroenterol Mot (in press)

40. Fox M, Fried M, Menne D, et al. The effect of tegaserod on esophageal function: a randomized controlled trial in healthy volunteers Aliment Pharmacol Ther 2006:24:1017-27.

41. Clouse RE, Staiano A, Alrakawi A. Topographic analysis of esophageal double-peaked waves. Gastroenterology 2000:118:469-76.

42. Sperandio M, Tutuian R, Gideon RM, et al. Diffuse esophageal spasm: not diffuse but distal esophageal spasm (DES). Dig Dis Sci 2003:48:1380-4

43. Crist J, Gidda JS, Goyal RK. Intramural mechanism of esophageal peristalsis: roles of cholinergic and noncholinergic nerves. Proc Natl Acad Sci U S A 1984;81:3595-9.

44. Yamato S, Spechler SJ, Goyal RK. Role of nitric oxide in esophageal peristalsis in the opossum. Gastroenterology 1992; 103:197-204

45. Fox M, Sweis R, Anggiansah A, et al. Sildenafil relieves symptoms and normalizes motility in patients with oesophageal spasm. Neurogastroenterol Mot 2007;19:798-803. Epub ahead of print: doi 10.1111/j.1365-2982.2007.00957.x

46. Bredenoord AJ, Weusten BL, Carmagnola S, et al. Doublepeaked high-pressure zone at the esophagogastric junction in controls and in patients with a hiatal hernia: a study using highresolution manometry. Dig Dis Sci 2004:49:1128-35.

47. Bredenoord AJ, Weusten BL, Timmer R, et al. Intermittent spatial separation of diaphragm and lower esophageal sphincter favors acidic and weakly acidic reflux. Gastroenterology 2006;130:33440.

48. Pandolfino JE, Zhang QG, Ghosh SK, et al. Transient lower esophageal sphincter relaxations and reflux: mechanistic analysis using concurrent fluoroscopy and high-resolution manometry. Gastroenterology 2006;131:1725-33.

49. Holloway RH, Hongo M, Berger K, et al. Gastric distention: a mechanism for postprandial gastroesophageal reflux. Gastroenterology 1985:89:779-84.

50. Bredenoord AJ, Weusten BL, Timmer R, et al. Sleeve senso versus high-resolution manometry for the detection of transient lower esophageal sphincter relaxations. Am J Physiol Gastrointest Liver Physiol 2005;288:G1190-4.

51. Scheffer RC, Gooszen HG, Hebbard GS, et al. The role of transsphincteric pressure and proximal gastric volume in acid reflux before and after fundoplication. Gastroenterology 2005;129:1900-

52. Bredenoord AJ, Weusten BL, Timmer R, et al. Gastrooesophageal reflux of liquids and gas during transient lower oesophageal sphincter relaxations. Neurogastroenterol Mot 2006;18:888-94

53. Brasseur JG, Ulerich R, Dai O, et al. Pharmacological dissection of the human gastro-oesophageal segment into three sphincteric components. J Physiol 2007:580(Pt. 3):961-75.

54. Lee JD, Anggiansah A, Anggiansah R, et al. The effects of age on the gastro-esophageal junction, esophageal motility and reflux disease. Clin Gastroenterol Hepatol 2007:5:1392-8.

55. Pandolfino JE, El-Serag HB, Zhang 0, et al. Obesity: a challenge to esophagogastric junction integrity. Gastroenterology 2006;130:639-49.

56. Wu JC, Mui LM, Cheung CM, et al. Obesity is associated with increased transient lower esophageal sphincter relaxation. Gastroenterology 2007;132:883-9.

57. Staiano A, Clouse RE. Detection of incomplete lower esophageal sphincter relaxation with conventional point-pressure sensors. Am J Gastroenterol 2001;96:3258-67.

58. Scheffer RC, Samsom M, Haverkamp A, et al. Impaired bolus transit across the esophagogastric junction in postfundoplication dysphagia. Am J Gastroenterol 2005;100:1677-84.

59. Tutuian R, Castell DO. Combined multichannel intralumina impedance and manometry clarifies esophageal function abnormalities: study in 350 patients. Am J Gastroenterol 2004:99:1011-9.
60. Cadiot G, Bruhat A, Rigaud D, et al. Multivariate analysis of pathophysiological factors in reflux oesophagitis. Gut 1997:40:167-74

61. Traube M, Peterson J, Siskind BN, et al. "Segmental aperistalsis" of the esophagus: a cause of chest pain and dysphagia. Am J Gastroenterol 1988;83:1381-5.

62. Massey BT, Dodds WJ, Hogan WJ, et al. Abnormal esophagea motility. An analysis of concurrent radiographic and manometric findings. Gastroenterology 1991:101:344-54.

63. Ghosh SK, Pandolfino JE, Zhang 0, et al. Deglutitive upper esophageal sphincter relaxation: a study of 75 volunteer subjects using solid-state high-resolution manometry. Am J Physiol Gastrointest Liver Physiol 2006;291:G525-31

64. Pandolfino JE, Ghosh SK, Zhang 0, et al. Quantifying EGJ morphology and relaxation with high-resolution manometry: a study of 75 asymptomatic volunteers. Am J Physiol Gastrointest Liver Physiol 2006:290:G1033-40.

65. Pandolfino J, Ghosh S, Rice J, et al. Classifying esophageal motility by pressure topography characteristics: a study of 400 patients and 75 controls. Am J Gastroenterol 2008;103:27-37.

66. Ghosh S, Pandolfino J, Rice J, et al. Impaired deglutative EGJ relaxation in clinical esophageal manometry: a quantitiative analysis of 400 patients and 75 controls. Am J Physiol Gastrointest Liver Physiol 2007;293:6878-85. Epub ahead of print: doi:101152/ ajpgi.00252.2007.

67. Clouse RE, Staiano A, Alrakawi A, et al. Application of topographical methods to clinical esophageal manometry. Am J Gastroenterol 2000;95:2720-30.

68. Holloway RH. Topographical clinical esophageal manometry: a better mousetrap or manometric overkill? Am J Gastroenterol 2000;95:2677-9.

69. Jee S, Pimentel M, Low K, et al. Novel redefinition and characterization of achalasia based on high resolution manometry. Gastroenterology 2007;132(4, Suppl 1):A-599 T1991.

70. Fox M, Anggiansah R, Wong $T$, et al. High resolution manometry in a tertiary referral centre: 100 consecutive patients with dysphagia. Gastroenterology 2007;132(4, Suppl 1):A-379 M1183.

71. Fox M, Forgacs I. Unexplained (non-cardiac) chest pain. Clin Med 2006;6:445-9.

72. Mattox HE 3rd, Richter JE, Sinclair JW, et al. Gastroesophagea $\mathrm{pH}$ step-up inaccurately locates proximal border of lower esophageal sphincter. Dig Dis Sci 1992;37:1185-91.

73. Agrawal A, Hila A, Tutuian R, et al. Clinical relevance of the nutcracker esophagus: suggested revision of criteria for diagnosis. J Clin Gastroenterol 2006;40:504-9.

74. Pehlivanov N, Liu J, Mittal RK. Sustained esophageal contraction: a motor correlate of heartburn symptom. Am J Physiol Gastrointest Liver Physiol 2001;281:G743-51.

75. Hunter JG, Swanstrom L, Waring JP. Dysphagia after laparoscopic antireflux surgery. The impact of operative technique. Ann Surg 1996;224:51-7.

76. Hunter JG, Smith CD, Branum GD, et al. Laparoscopic fundoplication failures: patterns of failure and response to fundoplication revision. Ann Surg 1999;230:595-604; discussion 604-6.

77. Draaisma WA, Rijnhart-de Jong HG, Broeders IA, et al. Five-yea subjective and objective results of laparoscopic and conventional Nissen fundoplication: a randomized trial. Ann Surg 2006;244:3441.

78. Hunt DR, Humphreys KA, Janssen J, et al. Preoperative esophageal transit studies are a useful predictor of dysphagia after fundoplication. J Gastrointest Surg 1999;3:489-95.

79. Baigrie R, Watson D, Myers J. Outcome of laparoscopic Nissen fundoplication in patients with disordered preoperative peristalsis. Gut 1997:40:381-5.

80. Fibbe C, Layer $\mathrm{P}$, Keller $\mathrm{J}$, et al. Esophageal motility in reflux disease before and after fundoplication: a prospective randomized, clinical, and manometric study. Gastroenterology 2001;121:5-14

81. Hakanson BS, Thor KB, Pope CE 2nd. Preoperative oesophageal motor activity does not predict postoperative dysphagia. Eur J Surg 2001;167:433-7.

82. Munitiz V, Ortiz A, Martinez de Haro LF, et al. Ineffective oesophageal motility does not affect the clinical outcome of open Nissen fundoplication. Br J Surg 2004;91:1010-4.

83. Bredenoord AJ, Draaisma WA, Weusten BL, et al. Mechanisms of inhibition of acidic and weakly acidic reflux after fundoplication. Gastroenterology 2007:132(4. Suppl 1):A-107 751

84. Alfa MJ, Inyckyj A, MacFarlane N, et al. Microbial overgrowth in water perfusion equipment for esophageal/rectal motility. Gastrointest Endosc 2002:55:209-13. 
85. Meshkinpour H, Eckerling G. Unexplained dysphagia: viscous swallow-induced esophageal dysmotility. Dysphagia 1996;11:125-8.

86. Pouderoux P, Shi G, Tatum RP, et al. Esophageal solid bolus transit: studies using concurrent videofluoroscopy and manometry. Am J Gastroenterol 1999;94:1457-63.

87. Desipio J, Friedenberg FK, Korimilli A, et al. High-resolution solidstate manometry of the antropyloroduodenal region. Neurogastroenterol Motil 2007;19:188-95.

88. Hveem K, Sun WM, Hebbard G, et al. Relationship between ultrasonically detected phasic antral contractions and antral pressure. Am J Physiol Gastrointest Liver Physiol 2001;281:G95-101.

89. Indireshkumar $\mathbf{K}$, Brasseur JG, Faas $\mathrm{H}$, et al. Relative contributions of "pressure pump" and "peristaltic pump" to gastric emptying. Am J Physiol Gastrointest Liver Physiol 2000;278:G60416.

90. Jones MP, Post J, Crowell MD. High-resolution manometry in the evaluation of anorectal disorders: a simultaneous comparison with water-perfused manometry. Am J Gastroenterol 2007:102:850-5

\section{Editor's quiz: GI snapshot}

\section{ANSWER}

From question on page 404

The patient had a cystic artery pseudoaneurysm, demonstrated on the arterial phase of the CT scan as a contrast-filled spherical mass. This finding was later confirmed by an angiogram (fig 1). Subsequently the supplying right hepatic vessels were embolised, having checked the portal flow to the right side of the liver. Her gastrointestinal bleeding subsequently stopped.

She went on to have a laparotomy which revealed a necrotic gallbladder containing a haematoma. There was a cholecystoduodenal fistula, explaining the apparent "ulcer" seen in the duodenum. This was repaired and she went on to have a cholecystectomy. Histology confirmed acute on chronic necrotic cholecystitis. The patient made an uneventful recovery.

One of the rare complications of cholecystitis is pseudoaneurysm formation of surrounding vessels. This may rupture into the gallbladder and bleed through a cholecystoduodenal fistula: a rare cause of upper gastrointestinal bleeding.

Gut 2008;57:423. doi:10.1136/gut.2006.114728a

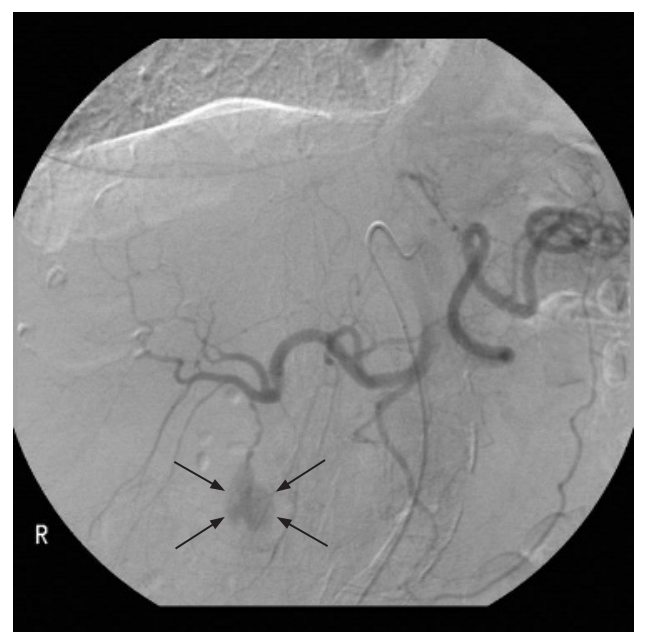

Figure 1 Angiogram demonstrating a cystic artery pseudoaneurysm (black arrows). 